\title{
An Experimental Study of Turbulent Lifted Flames at Elevated Pressures
}

\author{
T.F. Guiberti ${ }^{\mathrm{a}, *}$, W.R. Boyette ${ }^{\mathrm{a}}$, A.R. Masri ${ }^{\mathrm{b}}$, and W.L. Roberts ${ }^{\mathrm{a}}$ \\ ${ }^{a}$ King Abdullah University of Science and Technology (KAUST), CCRC, Thuwal 23955-6900, Saudi \\ Arabia. \\ ${ }^{b}$ School of Aerospace, Mechanical and Mechatronic Engineering, The University of Sydney, NSW, \\ 2006 Australia.
}

Prepared for submission to:

Combustion and Flame

Color figures for online version only.

*Corresponding Author:

Thibault F. Guiberti

Clean Combustion Research Center

4216-WS10, Al-Kindi West

King Abdullah University of Science and Technology (KAUST)

Thuwal 23955-6900, Saudi Arabia

Tel: + 966542492338

E-mail: thibault.guiberti@ kaust.edu.sa

\begin{abstract}
Studying the lift-off behavior of non-premixed jet flames is important to understanding the flame stabilization mechanisms in practical systems, including gas flares and combustors, and to improving the safety of pressurized fuel tanks in case of fuel leaks. This is typically done with the canonical configuration of an axisymmetric fuel jet issuing into a quiescent or co-flowing oxidizer and abundant data are available in the literature. However, most of these data were collected at normal or subatmospheric pressure and little data are available at elevated pressure and high Reynolds numbers, conditions relevant to practical configurations. The present study fills this gap by reporting lift-off height measurements of methane and ethane non-premixed jet flames for pressures up to 7 bar and $\operatorname{Re}=57,500$ in the presence of an air co-flow. Data are interpreted using Kalghatgi's model for the dimensionless lift-off height, which was previously proven successful for sub-atmospheric to normal pressures, as well as elevated pressure but only for low turbulent Reynolds numbers and propane. In this contribution, Kalghatgi's model has been shown to accurately predict the slope of the lift-off height $v s$ jet velocity curves at elevated pressure and large Reynolds number for methane and ethane. A new term, a function of the stoichiometric mixture fraction, the laminar burning velocity, and a turbulent Schmidt number, is also introduced to extend the predictive capabilities of Kalghatgi's model to configurations featuring a co-flow.
\end{abstract}

Keywords: lift-off; co-flow; pressure; laminar burning velocity; non-premixed; jet flame 


\section{Introduction}

In many industrial combustion-based systems involving flammable gases or liquids, fuel and air are not premixed upstream of the flame's location into the combustion chamber [1-3], forcing it to lift and, given the right conditions, stabilize away from the injector nozzle. This applies to industrial gas flares and combustors, as well as pressurized fuel tanks in case of fuel leaks. To understand the stabilization mechanisms of such flames, the lift-off of non-premixed flames has been studied extensively with the canonical configuration of an axisymmetric fuel jet issuing into a quiescent [48] or co-flowing oxidizer [9], generally air [10-14]. Different theories are published for the mechanism of stabilization and these include: the premixed flame theory [4], the turbulent intensity theory [15], the critical scalar dissipation concept [16], the large eddy concept $[17,18]$, and the edge-flame concept [19].

Regardless of which theory is most relevant, it is extremely useful to generate simple correlations that can predict the lift-off height of such flames under a range of operating conditions. Kalghatgi [15] proposed an expression for the lift-off height $h$ as a function of the bulk jet velocity $U_{j}$ and the laminar burning velocity $S_{L}$ :

$$
\frac{\rho_{f} S_{L} h}{\mu_{f}}=\mathrm{C}_{1} \frac{U_{j}}{S_{L}} \mathrm{~g}(\bar{\rho})
$$

where $\rho_{f}$ and $\mu_{f}$ are the fuel density and dynamic viscosity, $\mathrm{C}_{1}$ is an empirical constant close to 50, and $\mathrm{g}(\bar{\rho})$ is a density parameter computed as $\mathrm{g}(\bar{\rho})=0.04+0.46 \bar{\rho}+0.5 \bar{\rho}^{2}$ with $\bar{\rho}=\rho_{f} / \rho_{o}$. Subscript $o$ refers to the oxidizer. This expression was designed for fuel jets issuing into a quiescent environment and was shown to perform well for a range of fuels $[8,15]$. However, most of the data providing validation for Kalghatgi's model were obtained at atmospheric pressure. This database was recently extended to sub-atmospheric pressures $(0.6$ bar $\leq P \leq 1.0$ bar) for propane [20]. It was found that Kalghatgi's model remains valid at sub-atmospheric pressures for propane.

There are very few data available in the literature to verify if this expression is valid at elevated pressure. Effects of elevated pressure on the lift-off behavior of turbulent non-premixed jet flames have been examined recently [21, 22]. Bang et al. [21] showed that Kalghatgi's model continues to perform well for propane at pressures up to 5.5 bar. However, due to thermal power limitations of the high-pressure test-rig used by the authors, only moderate Reynolds numbers up to $\operatorname{Re}=5,500$ had been examined. Guiberti et al. [22] studied the lift-off behavior of methane jet flames over a similar pressure range but for larger Reynolds numbers up to $R e=19,000$. New stabilization mechanisms not 
observed previously for methane lifted flames at atmospheric pressure were uncovered at elevated pressure but the focus was not on challenging Kalghatgi's model. Therefore, it was not clear if Kalghatgi's model remains valid at elevated pressure and high Reynolds number. The present study intends to fill this gap by providing data in the canonical configuration of an axisymmetric jet issuing into an air co-flow for elevated pressures ( 1 bar $\leq P \leq 7$ bar) and two fuels, namely methane and ethane.

While Kalghatgi assumed a turbulent premixed flame stabilization mechanism [15], recent experiments [22] and simulations [23] provide strong support for the edge-flame theory at low lifted heights. Regardless of the dominant stability mechanism, and from an engineering point-of-view, the accuracy and usefulness of a predictive tool may outweigh certain deficiencies in its conceptual construct. This contribution proceeds with this understanding and does not necessarily commit to a particular mechanism for stabilization. It simply employs Kalghatgi's formulation as a useful launch pad to extend it scope of relevance to elevated pressures, other fuels, and to conditions involving a range of co-flow velocities.

\subsection{Effects of the co-flow}

Kalghatgi's model was designed for fuel jets issuing into a quiescent environment and does not account for the presence of a co-flow. Therefore, efforts were made to extend the validity of this model to configurations featuring a co-flow [24-27]. In [25-27], an effective velocity $U_{\text {eff }}$ is defined as:

$$
U_{e f f}=U_{j}+\mathrm{C}_{2}\left(\frac{\rho_{o}}{\rho_{f}}\right)^{\frac{1}{2}} U_{c}
$$

where $\mathrm{C}_{2}$ is an empirical constant and $U_{c}$ stands for the co-flow velocity. It is shown that replacing $U_{j}$ by $U_{\text {eff }}$ allows capturing the effects of the co-flow by collapsing the $h v s U_{\text {eff }}$ curves recorded for different co-flow velocities onto a single curve. In these three studies [25-27], this expression is challenged only for methane, meaning that the usefulness of the term related to the oxidizer to fuel density ratio cannot be validated experimentally. Physically, this term relates to Kelvin-Helmholtz instabilities, which produce vortices controlling mixing in the shear layer between fuel and oxidizer streams [28-31] and whose strength is proportional to $\left(\rho_{o} / \rho_{f}\right)^{1 / 2}$ [32]. In addition, the constant $\mathrm{C}_{2}$ is obtained by best-fit of the data and it is argued that it may vary with fuel and burner dimensions [25]. Best fit corresponds to $\mathrm{C}_{2}=5.2$ for methane and a fuel tube inner diameter of $10 \mathrm{~mm}$ in [25]. A different value of $C_{2}=50$ is found to provide a good collapse of the data from $[10,11,27]$ for methane and fuel tube inner diameters of 3.5, 4.0, 4.8, and $5.0 \mathrm{~mm}$. Therefore, the expression of Eq. (2) for the 
effective velocity offers limited potential as an engineering tool for the prediction of lift-off heights because the constant $\mathrm{C}_{2}$ is not predicted and must be calibrated.

With a conceptual view on the mixing process between fuel and oxidizer concentric jets, Han and Mungal [24] proposed the following expression for the stoichiometric velocity $U_{s}$, such as would be experienced by the lifted flame at its base:

$$
U_{s}=\mathrm{Z}_{\mathrm{st}} U_{j}+\left(1-\mathrm{Z}_{\mathrm{st}}\right) U_{c}
$$

where $Z_{\text {st }}$ stands for the stoichiometric mixture fraction. By analogy with [25-27], it is possible to define an effective velocity, to replace the bulk jet velocity in Kalghatgi's model, as follows:

$$
U_{e f f}=U_{j}+\frac{\left(1-\mathrm{Z}_{\mathrm{st}}\right)}{\mathrm{Z}_{\mathrm{st}}} U_{c}
$$

The benefit of Eq. (3) is that effects of the co-flow may now be predicted because the stoichiometric mixture fraction can be easily calculated. It is $\mathrm{Z}_{\mathrm{st}}=0.055$ for methane, yielding $U_{\text {eff }}=U_{j}+17.2 U_{c}$. Equation (4) and Eq. (2) with $\mathrm{C}_{2}=50$ do not predict the same effective velocity for methane jets in air. In addition, Eq. (3) does not include any density weighted terms. Finally, Eq. (3) is only valid for a Schmidt number of unity, which does not account for effects of fuel and turbulence. To the best of the authors' knowledge, Eq. (4) has never been challenged using flame lift-off data.

\subsection{Inadequacy of Kalghatgi's model for low jet velocities}

Whether it is calculated with Eq. (2) or (3), the effective velocity increases linearly with the co-flow velocity. This is compatible with numerous experimental observations where the lift-off height increases linearly with the co-flow velocity at fixed bulk jet velocity [10, 11, 25, 27]. Based on Eq. (1), extrapolating the $h$ vs $U_{j}$ curves towards $U_{j}=0$ yields $h=0$ for a jet issuing into a quiescent environment. Therefore, in the presence of a co-flow, extrapolating the $h v s U_{j}$ curves towards $U_{j}=0$ is expected to produce positive $\mathrm{Y}$-intercepts. Careful examination of many of the lift-off data available in the literature shows that this is not always the case. The $h v s U_{j}$ curves of Moore and Lyons [27] exhibit negative extrapolated Y-intercepts for methane and $U_{c} \leq 0.41 \mathrm{~m} . \mathrm{s}^{-1}$. Those of Guiberti et al. [22] show negative extrapolated Y-intercepts for methane and $U_{c} \leq 0.40 \mathrm{~m} \cdot \mathrm{s}^{-1}$ at 2 bar and $U_{c} \leq 0.30 \mathrm{~m} . \mathrm{s}^{-1}$ at 6 bar. A similar behavior is observed in [33] for a range of hydrocarbon fuels and $U_{c}=0.10 \mathrm{~m} \cdot \mathrm{s}^{-1}$, in [34] for diluted co-flows with $U_{c}=0.10 \mathrm{~m} \cdot \mathrm{s}^{-1}$ and in [35] for diluted co-flows with $U_{c}=0.27 \mathrm{~m} . \mathrm{s}^{-1}$. Negative Y-intercepts are also observed in configurations not featuring a co-flow 
$\left(U_{c}=0\right)$ in $[11,20]$. Kalghatgi's model enhanced to include co-flow effects using an effective velocity (see Eqs. (2) and (4)) cannot predict this behavior and it is somewhat surprising that this behavior is not discussed in any of the above studies that utilize or refer to Kalghatgi's model.

Using simple scaling relations, Upatnieks et al. [36] came up with the following expression for the lift-off height in absence of a co-flow:

$$
h=C_{3} \frac{\alpha\left(U_{j}-\frac{S_{L}}{Z_{s t}}\right)}{S_{L}^{2}}
$$

Where $\mathrm{C}_{3}$ is a constant and $\alpha$ is the thermal diffusivity. This expression shares many features with Kalghatgi's expression (Eq. (1)) but includes another term $-S_{L} / Z_{\mathrm{st}}$ that yields $h<0$ for $U_{j}=0$. It is argued in [36] that the term $-S_{L} / \mathrm{Z}_{\mathrm{st}}$ can often be neglected with respect to $U_{j}$. However, $S_{L} / \mathrm{Z}_{\mathrm{st}}$ reaches a non-negligible $10 \%$ of $U_{j}$ for methane at 1 bar if $U_{j}=62 \mathrm{~m} \cdot \mathrm{s}^{-1}$, which is larger than the bulk jet velocities typically examined in the studies mentioned above. Therefore, it is possible that the $-S_{L} / \mathrm{Z}_{\mathrm{st}}$ term must be accounted for to explain the lift-off behavior of jet flames issuing into quiescent environment or into a co-flow for low to intermediate bulk jet velocities. In addition, it is known that Kalghatgi's expression (Eq. (1)) is not valid for low bulk jet velocities yielding laminar or transitional bulk jet Reynolds numbers [12].

In summary, while useful ingredients and partial expressions have been described in the literature, there is currently no model able to capture quantitatively the effects of the co-flow on the lift-off height and that is valid for a range of fuels, burner dimensions, and pressures. The present study intends to fill this gap using data recorded for two fuels over a range of co-flow velocities and pressures, as well as data available in the literature. 


\section{Experimental methods}

Experiments are conducted in the high-pressure combustion duct (HPCD) available at the Clean Combustion Research Center in KAUST. Its main features are shown in Fig. 1 and the reader is referred to $[22,37]$ for more details. The burner assembly consists of a $0.57-\mathrm{m}$ long stainless-steel fuel tube featuring a $D=3.4-\mathrm{mm}$ inner diameter and a $4.5-\mathrm{mm}$ outer diameter with a square exit profile. The fuel tube, which supplies methane or ethane, is surrounded by a $0.25-\mathrm{m}$ diameter co-flow nozzle providing a uniform air co-flow at velocities $0.20 \mathrm{~m} . \mathrm{s}^{-1} \leq U_{c} \leq 0.80 \mathrm{~m} . \mathrm{s}^{-1}$. The HPCD is aircooled and its pressure is regulated by a dome-loaded back-pressure regulator. Therefore, co-flow air must be supplied continuously to dissipate the flame's thermal power and maintain the desired pressure set-point. In this study, the fuel tube diameter is smaller than that used previously in [22] for methane only, $D=4.6 \mathrm{~mm}$, and this allows accommodating for the larger volumetric energy density of ethane and maintain the thermal power within acceptable limits.

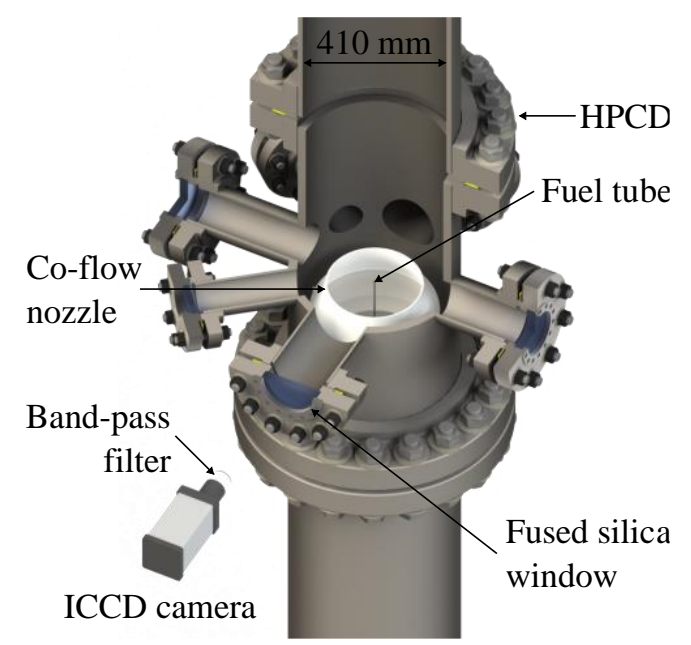

Fig. 1: Schematic of the experimental setup.

The fuel mass flow rate is regulated using two thermal mass flow controllers (Brooks SLA5851 and SLA5853) featuring different full scales (49 and $189 \mathrm{slpm}$ and 30 and 114 slpm for methane and ethane, respectively) to ensure that metering is realized with optimal accuracy. These devices are calibrated in-house using a gas flow calibrator (MesaLabs ML-1020) before experiments to maintain an accuracy better than $1 \%$. The smallest bulk jet Reynolds number $\mathrm{Re}_{\mathrm{j}}$ considered in this study is $\operatorname{Re}_{j}=3700$ which may be sufficiently high so that laminarization is unlikely. The air flow rate in the co-flow nozzle is monitored by a thermal mass flow meter (FCI STP100) and is known with an accuracy of $\pm 10 \%$.

Figure 2 shows 15 s exposure broadband flame images recorded with a DSLR camera (Nikon D810 with AF-S Nikkor 24-120 mm lens, F/22, iso250) for four selected operating conditions yielding lifted flames. Because these flames are longer than the widest HPCD side window (150-mm diameter), the 
burner is mounted on a vertical translation stage so that different heights above the burner may be imaged. A collection of images is then recorded at different successive burner heights before being stitched together to yield the images shown in Fig. 2. In order to compensate for large differences in the flames' luminosity, neutral density filters of various optical densities are used and this is quantified by an intensity factor in Fig. 2. This figure shows that pressure, fuel, and jet velocity have a large

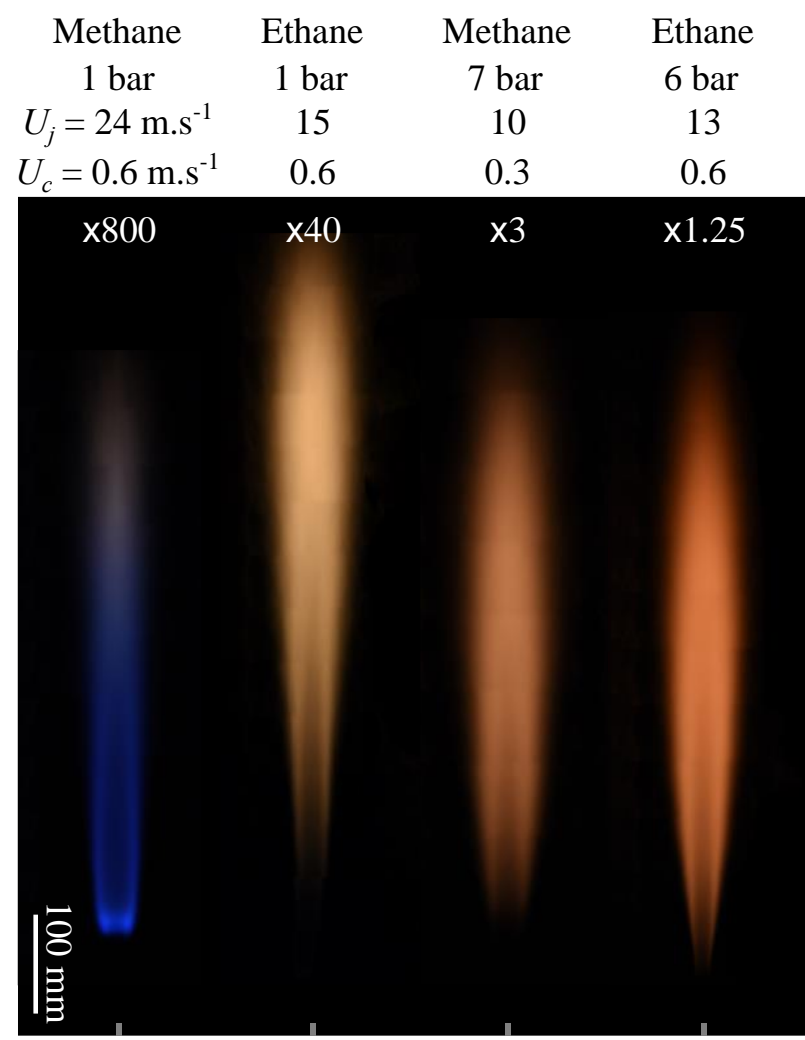

Fig. 2: Long exposure direct flame images. Images taken at different heights are stitched together. An intensity factor is provided for each image to allow comparison of the flames' luminosity.

influence on important flame properties such as their length and soot loading, but this is not the main focus of this study and these flame images are shown here only for illustration purposes. However, regardless of fuel and pressure, the base of the lifted flames examined here is always blue and soot free. This blue flame base can only be seen in the left picture of Fig. 2 (recorded with methane at $P=1$ bar) because soot luminosity is very intense in the other flames and this imposes camera settings that make the detection of the much less intense blue flame base difficult.

The lift-off height is measured with a $1024 \times 1024$ intensified CCD camera (Princeton Instruments PIMAX4) operated at $5 \mathrm{~Hz}$ and equipped with a band-pass filter (Asahi Spectra ZBPA310) to image the flame's $\mathrm{OH}^{*}$ chemiluminescence. The procedure chosen to post-process images and infer the lift-off height is summarized here and illustrated with Fig. 3. A typical $\mathrm{OH}^{*}$ chemiluminescence snapshot, recorded for methane at $P=4$ bar, is shown in Fig. 3a. The corresponding histogram of pixels counts is first computed, yielding Fig. 3b. Typically, such histogram exhibits a local minimum. Pixels with 
counts lower that the counts at the local minimum correspond to the background while pixels with larger counts are in regions where $\mathrm{OH}^{*}$ chemiluminescence is detected. In the example of Fig. $3 \mathrm{~b}$, the local minimum corresponds to 456 counts but this value depends on the soot loading and, therefore, increases with pressure and is globally larger for ethane than for methane. This threshold value can then be used to binarize the $\mathrm{OH}^{*}$ chemiluminescence snapshot, separating zones with and without $\mathrm{OH}^{*}$ chemiluminescence (Fig. 3c) [38]. A total of 500 snapshots are collected for each operating condition. The corresponding 500 binarized images are then averaged to yield the spatial distribution of probability to find $\mathrm{OH}^{*}$ chemiluminescence, i.e., a flame. This is shown in Fig. 3d. Along the burner's centerline, the lift-off height $h$ is defined by the height above the nozzle giving a probability of 0.5 . The uncertainty on the measured lift-off heights, which is associated with the spatial resolution of the optical arrangement, is smaller than $5 \%$. The size of symbols in the figures showing the liftoff heights gives an idea of the confidence range.

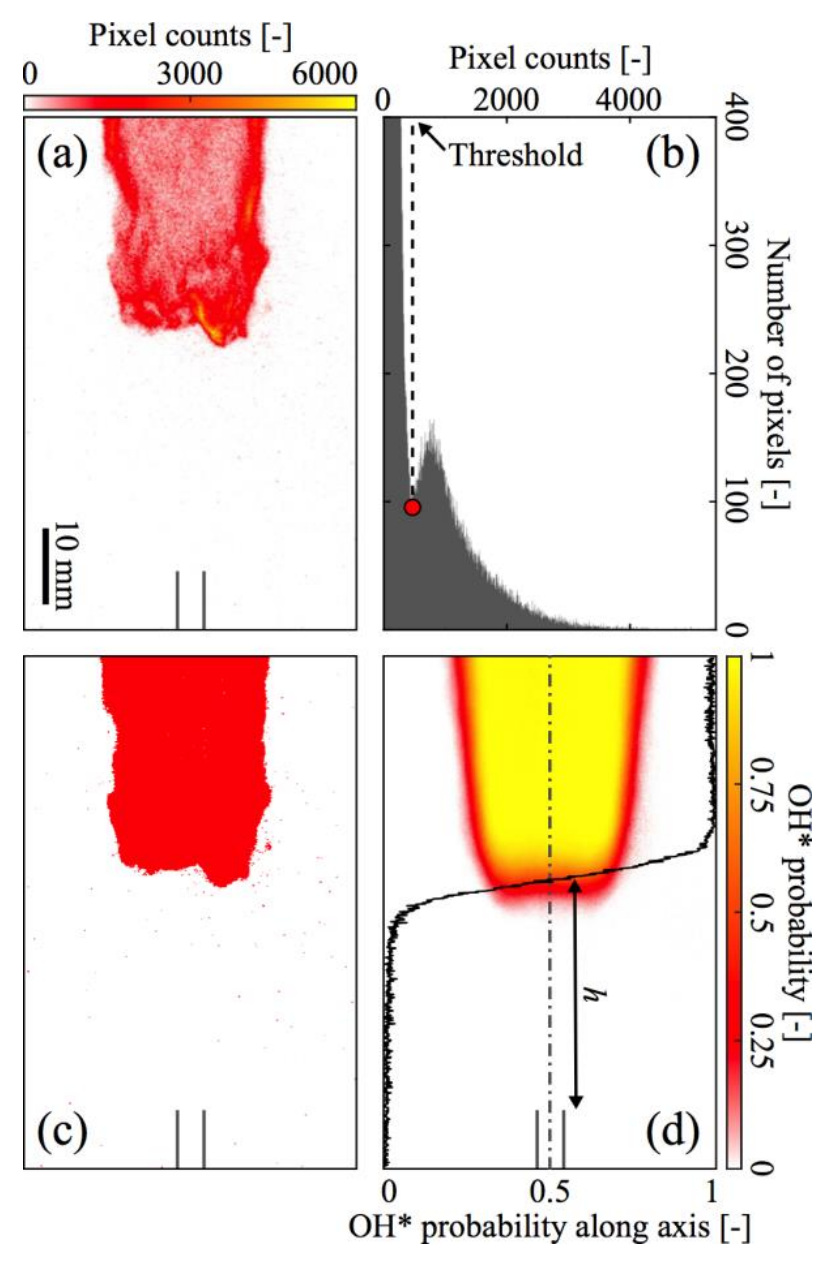

Fig. 3: (a) Snapshot of $\mathrm{OH}^{*}$ chemiluminescence recorded for methane at $P=4$ bar. (b) Pixels counts histogram. (c) Binarized $\mathrm{OH}^{*}$ chemiluminescence. (d) Probability to find $\mathrm{OH}^{*}$ chemiluminescence and its profile along the burner axis. 


\section{Results and discussion}

The lift-off behavior of non-premixed jet flames is first analyzed in Sec. 3.1 by means of a parametric study where pressure ( 1 bar $\leq P \leq 7$ bar), bulk jet velocity $\left(4 \mathrm{~m} \cdot \mathrm{s}^{-1} \leq U_{j} \leq 30 \mathrm{~m} \cdot \mathrm{s}^{-1}\right.$ ), co-flow velocity $\left(0.20 \mathrm{~m} \cdot \mathrm{s}^{-1} \leq U_{c} \leq 0.80 \mathrm{~m} \cdot \mathrm{s}^{-1}\right)$, and fuel (methane and ethane) are varied. In Sec. 3.2, Kalghatgi's model for the dimensionless lift-off height is challenged with these new data at elevated pressure. In Sec. 3.3, data recorded at elevated pressure as well as data already available in the literature are used to formulate an extension of Kalghatgi's model that accounts for effects of the coflow.

\subsection{A parametric study of the lift-off height}

Figure 4a shows the measured lift-off height $h$ as a function of the bulk jet velocity $U_{j}$ for methane, for seven pressures in the range 1 bar $\leq P \leq 7$ bar, and a co-flow velocity of $U_{c}=0.30 \mathrm{~m} . \mathrm{s}^{-1}$. First, regardless of pressure, there is a linear relationship between $h$ and $U_{j}$, which is compatible with Eq. (1). Second, the slope $\kappa$ of the $h$ vs $U_{j}$ curves (taken equal to the slope of the line providing the best fit of the data in the least square sense) is positive and increases slowly but monotonically with pressure. Third, the jet velocity yielding a given lift-off height decreases with pressure. Note that linear extrapolation towards the Y-axis (see dashed lines) does not yield $h=0$ for most of these curves, which is not in accordance with Eq. (1). This is partly due to the non-zero co-flow velocity that is not accounted for in Eq. (1). Also note that the extrapolated $\mathrm{Y}$-intercepts are negative for $P<6$ bar, which is a feature already observed in [22].

Figure $4 \mathrm{~b}$ shows the measured lift-off height $h$ as a function of the bulk jet velocity $U_{j}$ for ethane, the same pressure range ( 1 bar $\leq P \leq 7$ bar), and the same co-flow velocity of $U_{c}=0.30 \mathrm{~m} \cdot \mathrm{s}^{-1}$. Overall, the lift-off height is much smaller for ethane than for methane for the same bulk jet velocity and coflow velocity. In addition, the data roughly collapse onto one curve for all the pressures investigated, a feature that is not shared with methane. More importantly, all the conditions examined for ethane at elevated pressure yield lift-off heights smaller than $h=0.015 \mathrm{~m}$, which corresponds to $h / D \approx 4.5$. It could then be argued that, for ethane, the flame base sits closer to the nozzle exit plane $(h / D<6)$ where the center of the jet is still dominated by the potential core $[39,40]$. While increasing the bulk jet velocity to values larger than $U_{j}=18 \mathrm{~m} \cdot \mathrm{s}^{-1}$ is not possible for ethane at elevated pressure due to thermal limitations of the HPCD, lift-off heights corresponding to bulk jet velocities up to $U_{j}=29 \mathrm{~m} . \mathrm{s}^{-}$ ${ }^{1}$ are shown in Fig. $4 \mathrm{~b}$ for $P=1$ bar. Even if $h$ increases monotonically with $U_{j}$ over the whole range investigated for ethane at $P=1 \mathrm{bar}$, there is a well-marked change in the slope of the $h v_{s} U_{j}$ curve 

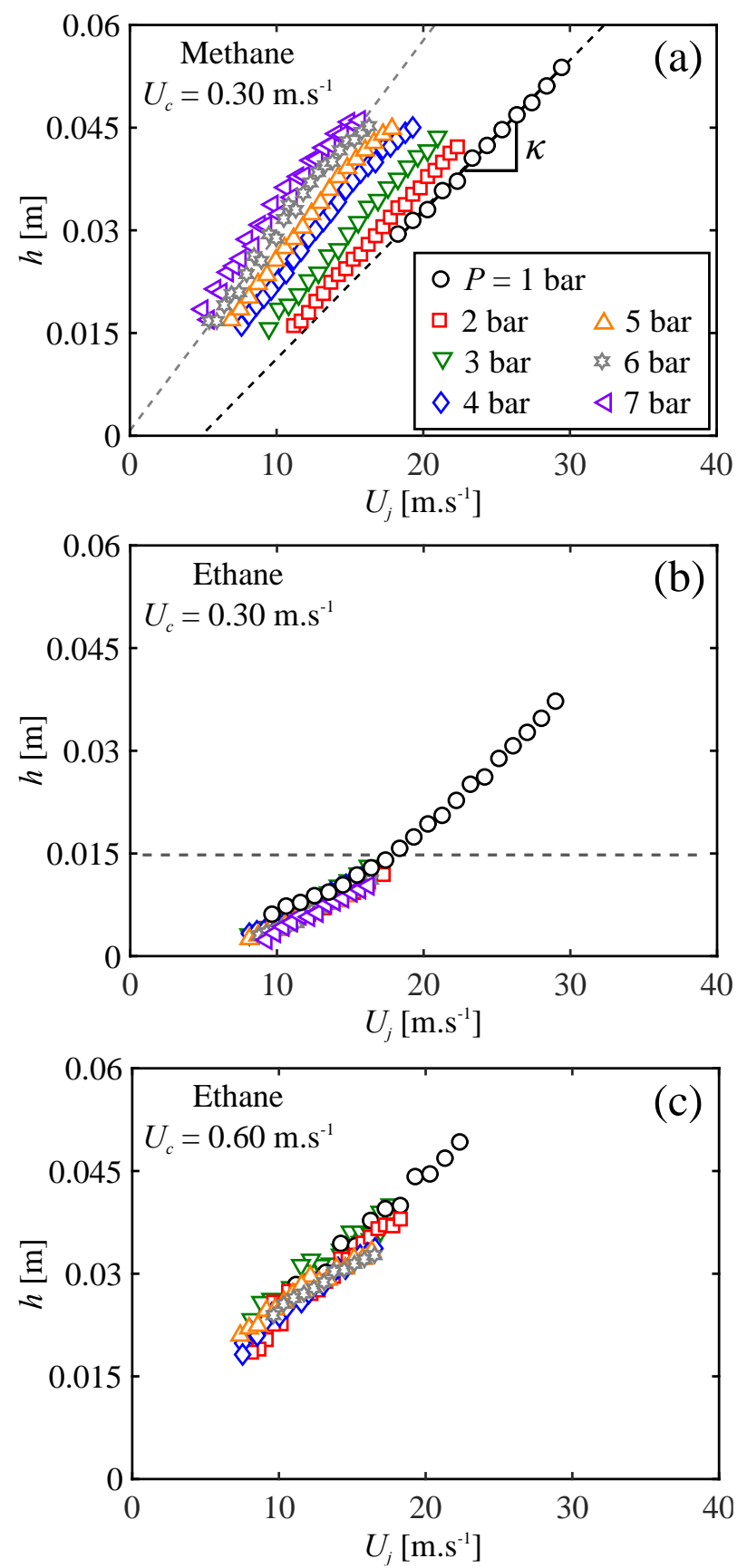

Fig. 4: (a) Lift-off height as a function of the bulk jet velocity for methane at different pressures and a co-flow velocity of $U_{c}=0.30 \mathrm{~m} \cdot \mathrm{s}^{-1}$. (b) Same for ethane and $U_{c}=0.30 \mathrm{~m} \cdot \mathrm{s}^{-1}$. (c) Same for ethane and $U_{c}=0.60 \mathrm{~m} \cdot \mathrm{s}^{-1}$.

around $U_{j}=18 \mathrm{~m} \cdot \mathrm{s}^{-1}$. One explanation for this behavior is that, with increasing jet velocity, the flame base exits the flow development region at this bulk jet velocity that corresponds to $h / D \approx 4.5$.

This non-linear behavior cannot be predicted by Kalghatgi's model (Eq. (1)) which is not meant to capture the lift-off behavior so close to the nozzle. To challenge Kalghatgi's model in regions of the flow where it was meant to perform well, additional experiments were conducted with ethane and a twice larger co-flow velocity $U_{c}=0.60 \mathrm{~m} . \mathrm{s}^{-1}$. Results are shown in Fig. 4c. The lift-off height now satisfies $h / D>5.4$ for all the pressures investigated. Even for these larger co-flow velocities, the $h$ vs $U_{j}$ curves continue to roughly collapse onto one curve. However, careful examination suggests 
that the slope $\kappa$ of the $h v s U_{j}$ curves decreases slowly with pressure, which is the opposite trend as the one observed for methane in Fig. 4a. Understanding effects of fuel and pressure on the slope $\kappa$ of the $h$ vs $U_{j}$ curves is important because $\kappa$ is the only quantity that Kalghatgi's model aims at predicting.

To promote a more quantitative analysis, the measured slopes $\kappa$ (hollow symbols) are plotted as a function of pressure for methane $\left(U_{c}=0.30 \mathrm{~m} \cdot \mathrm{s}^{-1}\right)$ and ethane $\left(U_{c}=0.60 \mathrm{~m} \cdot \mathrm{s}^{-1}\right)$ in Fig. 5. The slope increases slowly but continuously from $\kappa=2.3 \times 10^{-3} \mathrm{~s}$ at $P=1$ bar to $\kappa=3.0 \times 10^{-3} \mathrm{~s}$ at $P=7$ bar for methane. Conversely, the slope decreases slowly from $\kappa=2.0 \times 10^{-3}$ s at $P=1$ bar to $\kappa=1.3 \times 10^{-3} \mathrm{~s}$ at $P=6$ bar for ethane.

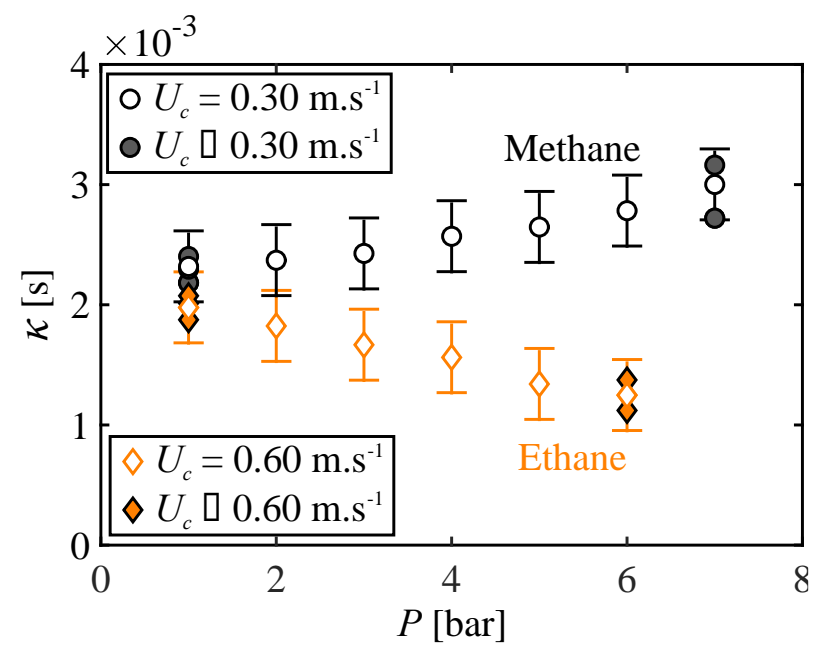

Fig. 5: Slope $\kappa$ as a function of pressure for methane with $U_{c}=0.30 \mathrm{~m} \cdot \mathrm{s}^{-1}$ and ethane with $U_{c}=0.60 \mathrm{~m} \cdot \mathrm{s}^{-1}$.

Kalghatgi's model was initially designed for jets in quiescent air and do not include any terms related to the co-flow velocity. Therefore, it is interesting to check if modifying the co-flow velocity has an influence on the slope $\kappa$. This is done here by conducting additional experiments for a range of coflow velocities and the corresponding $h$ vs $U_{j}$ curves are shown in Figs. 6a and 6b for methane and ethane, respectively. At $P=1$ bar and regardless of fuel, the lift-of height increases with the co-flow velocity at any fixed bulk jet velocity but the slope $\kappa$ is not varying significantly with the co-flow velocity. By extrapolation, this result suggests that the slope $\kappa$ would also be the same in quiescent air with $U_{c}=0 \mathrm{~m} \cdot \mathrm{s}^{-1}$. It can then be argued that Kalghatgi's expression could also be used to predict the slope of these $h$ vs $U_{j}$ in the presence of a co-flow.

Figures $6 \mathrm{a}$ and $6 \mathrm{~b}$ also show the $h$ vs $U_{j}$ curves measured for different co-flow velocities and both fuels at elevated pressures of $P=7$ bar for methane and $P=6$ bar for ethane. It is evident that the coflow velocity now has a much larger influence on the $h v s U_{j}$ curves. For each fuel, it is possible to define two regions separated by a critical co-flow velocity below which the slope $\kappa$ is not sensitive to the co-flow velocity and above which the slope $\kappa$ decreases with the co-flow velocity. In fact, if the 

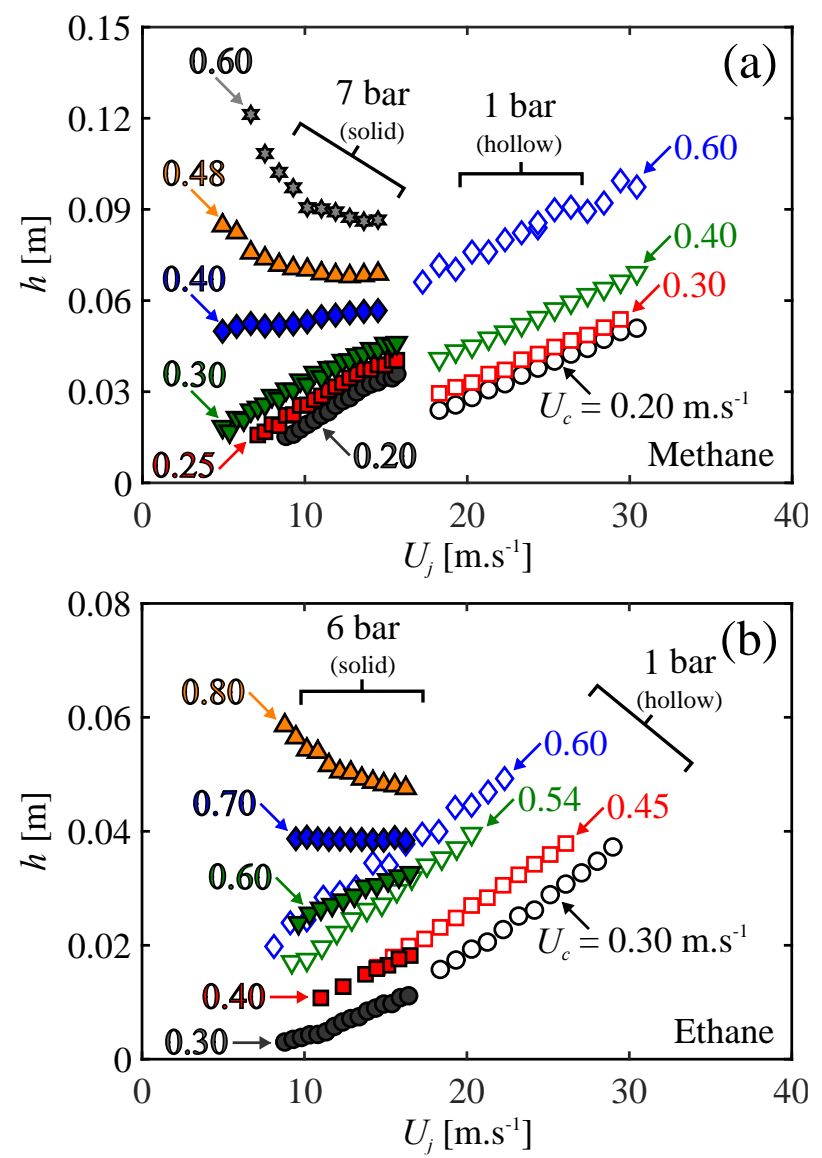

Fig. 6: (a) Lift-off height as a function of the bulk jet velocity for methane at $P=1$ and 7 bar and different coflow velocities. (b) Same for ethane at $P=1$ and 6 bar.

co-flow velocity becomes large enough, the lift-off height decreases with the bulk jet velocity in a non-linear fashion and the slope $\kappa$ cannot be clearly defined. The critical co-flow velocity lies between $U_{c}=0.30 \mathrm{~m} . \mathrm{s}^{-1}$ and $U_{c}=0.40 \mathrm{~m} \cdot \mathrm{s}^{-1}$ for methane at $P=7$ bar. For ethane at $P=6$ bar, this critical velocity is larger and ranges from $U_{c}=0.60 \mathrm{~m} \cdot \mathrm{s}^{-1}$ to $U_{c}=0.70 \mathrm{~m} \cdot \mathrm{s}^{-1}$. Also note that, above this critical co-flow velocity, the lift-off height increases more rapidly with the co-flow velocity. Mechanisms underlying the effects of large co-flow velocities and the reduction of the slope $\kappa$ have been the topic of [22]. Reduction of the slope $\kappa$ when the co-flow velocity is increased was attributed in [22] to a change in the flame stabilization mechanism from non-premixed edge-flames to premixed flames. Of particular importance here is that for any fuel and pressure examined, there exists a co-flow velocity range within which the slope $\kappa$ remains unchanged. This range is bounded by zero and a critical coflow velocity, function of fuel and pressure. The slopes measured within this range are also shown in Fig. 5 (solid symbols). Beyond this critical co-flow velocity, the slope reverses due to a transition in the stabilization mechanism. 


\subsection{Validation of Kalghatgi's model at elevated pressure}

Since there exists a critical co-flow velocity below which the slope $\kappa$ is not a function of the co-flow velocity, such slope should be predictable using Kalghatgi's model (Eq. (1)) even if it does not account for the influence of the co-flow. This is challenged here with the new data available at elevated pressure. Rearranging the terms of Eq. (1) yields the following expression for the slope $\kappa$ :

$$
\kappa=\frac{\mathrm{C}_{1} \mathrm{~g}(\bar{\rho}) \mu_{f}}{\rho_{f} S_{L}^{2}}
$$

The slope is then very sensitive to the laminar burning velocity, which appears at the denominator and is squared. Figure 7a plots the laminar burning velocity as a function of pressure for methane using data available in the literature [41-45]. The laminar burning velocity computed with the premixed laminar flame-speed calculation module available in Chemkin-Pro [46] and the USCII skeletal chemistry mechanism [47] is also plotted as well as that obtained using an analytical expression based on the overall reaction order $\mathrm{n}$ [48]: $S_{L}=0.38 P^{(\mathrm{n}-2) / 2} \approx 0.38 P^{-0.5}$. The laminar burning velocity decreases with pressure and this is a well-known feature of methane. More importantly, there are significant discrepancies between the models and the experiments, ranging from $6 \%$ at $P=1$ bar to $26 \%$ at $P=5$ bar. Since the laminar burning velocity is squared in Eq. (6), this translates into imprecisions of $32 \%$ at $P=1$ bar and $52 \%$ at $P=5$ bar in the predictions of the slope $\kappa$. Therefore, and given this uncertainty, it would be more appropriate not to compare the measured slopes of the lift-off heights but rather to use the experimentally measured slope to extract the laminar burning velocity from Kalghatgi's correlation. This then will be compared to values of the laminar burning velocity available in the literature. This is done by rearranging Eq. (1) as follows:

$$
S_{L}=\left(\frac{\mathrm{C}_{1} \mathrm{~g}(\bar{\rho}) \mu_{f}}{\rho_{f} \kappa}\right)^{\frac{1}{2}}
$$

Figure 7a shows the laminar burning velocity computed using the measured slopes and Eq. (7) for methane and all the conditions included in Fig. 5. The laminar burning velocity predicted by Eq. (7) decreases from $S_{L}=0.40 \mathrm{~m} . \mathrm{s}^{-1}$ at 1 bar to $S_{L}=0.13 \mathrm{~m} . \mathrm{s}^{-1}$ at 7 bar. Agreement with values obtained from the literature, simulations, and the overall reaction order is very good and differences lie within the rather larger uncertainties of the measured and computed data. This confirms that Kalghatgi's model is able to predict the slope of the $h v s U_{j}$ curves for methane up to $P=7 \mathrm{bar}$, as long as the coflow velocity does not exceed a critical value, which is larger than $U_{c}=0.60 \mathrm{~m} . \mathrm{s}^{-1}$ at $P=1$ bar and 
larger than $U_{c}=0.30 \mathrm{~m} \cdot \mathrm{s}^{-1}$ at $P=7$ bar. This also suggests that Kalghatgi's model would yield accurate predictions of the slope in absence of a co-flow.
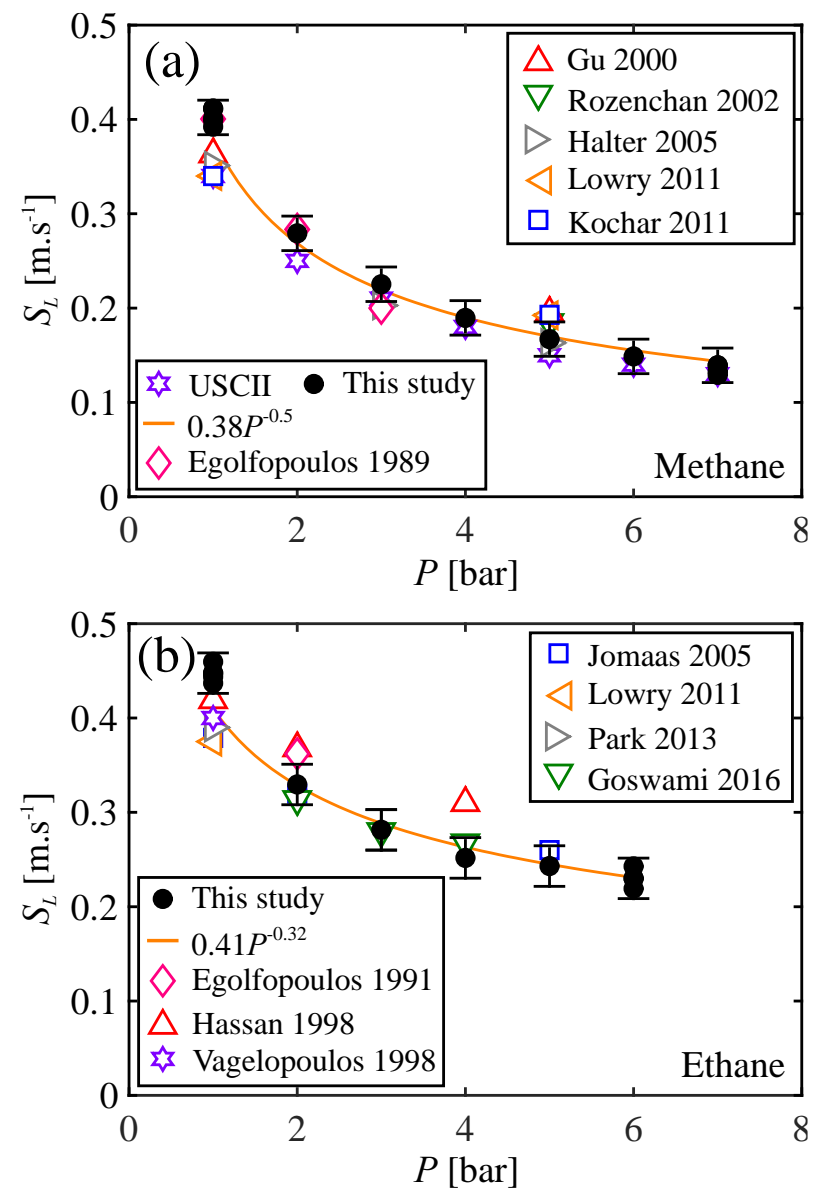

Fig. 7: (a) Laminar burning velocity as a function of pressure for methane, computed with Eq. (7) (black solid symbols), the USCII mechanism, the overall reaction order, or taken from the literature. (b) Same for ethane.

Figure $7 \mathrm{~b}$ plots the laminar burning velocity computed using the measured slopes and Eq. (7) for ethane and all the conditions included in Fig. 5. The laminar burning velocity predicted by Eq. (7) also decreases with pressure, albeit at a slower rate than methane, with $S_{L}=0.44 \mathrm{~m} \cdot \mathrm{s}^{-1}$ at 1 bar and $S_{L}=0.23 \mathrm{~m} . \mathrm{s}^{-1}$ at 6 bar. These values may also be compared to that from the literature [44, 49-54] and the overall reaction order ( $\mathrm{n} \approx 1.36$ for ethane [55]), yielding $S_{L} \propto P^{-0.32}$. Figure $7 \mathrm{~b}$ shows that Eq. (7) captures well trends and numbers of the laminar burning velocity as a function of pressure for ethane. Therefore, Kalghatgi's model also performs well for ethane up to $P=7$ bar. Note that, in the above, the methane and ethane overall reaction orders take different but constant values. This is a simplification because the overall reaction order is known to be a weak function of pressure [48]. However, laminar burning velocity predictions based on a constant overall reaction order are satisfying (see Fig. 7) and neglecting effects of pressure on the overall reaction order is not expected to influence the results discussed here. 
The adequacy of Kalghatgi's model was proven previously for propane up to $P=5.5$ bar but only up to $\operatorname{Re}=5,500$ [21]. Reynolds numbers examined in the present study peak at $\operatorname{Re}=22,000$ for methane and $\operatorname{Re}=57,500$ for ethane. It is then safe to conclude that the performances of Kalghatgi's model in predicting the slope of the $h v s U_{j}$ curves are good over a range of fuels, including at least $\mathrm{C}_{1}$ to $\mathrm{C}_{3}$ alkanes, and over a large range of Reynolds numbers.

As mentioned earlier, such statement is only valid if the co-flow velocity does not exceed a critical value, which is a function of fuel and pressure. Slope inversion $(\kappa=0)$ was found to correspond roughly to $U_{c}=3 S_{L}$ in [22] using data for methane at $P=3$ and 6 bar and ethylene at $P=1$ bar [10]. This is also verified with new data reported here for ethane at $P=6$ bar with a slope inversion observed for $U_{c}=0.70 \mathrm{~m} . \mathrm{s}^{-1} \approx 3.0 S_{L}$. Because slope inversion is attributed to a transition from nonpremixed to premixed modes of combustion [10,22], there must exist a co-flow velocity range, within which $U_{c}<3 S_{L}$, where the flames are partially-premixed. In this range, the slope of $h v s U_{j}$ curves decreases progressively with the co-flow velocity even though it remains positive. Values of the coflow velocity below which slope is shown to remain unaffected are summarized in Tab. 1. Table 1 includes data from the present study and [10, 22], corresponding to four different fuels and four different pressures. It shows that the slope is not a function of the co-flow velocity if the latter does not exceed a critical value close to 1.5 to 2 times the laminar burning velocity. Note that, in some cases, the slope reduction due to large co-flow velocities cannot be observed because blow-out occurs first when the co-flow velocity is increased [10]. This is, for example, the case for methane at $P=1$ bar. Also note that, while transition from non-premixed to premixed modes of combustion is associated with increased lift-off heights $[10,22]$, it is not possible to predict such transition with a criterion based on a lift-off height $h$ or $h / D$. Indeed, Fig. 6 clearly shows that the same lift-off height $h=0.08 \mathrm{~m}$ features a positive slope (edge-flame) for methane for $P=1$ bar and $U_{c}=0.60 \mathrm{~m} \cdot \mathrm{s}^{-1}$ while it is negative (premixed or partially-premixed flame) for $P=7$ bar and $U_{c}=0.48 \mathrm{~m} . \mathrm{s}^{-1}$. A similar behavior is observed for ethane.

Tab. 1: Measured co-flow velocity below which the slope $\kappa$ of the $h v s U_{j}$ is shown to remain unaffected.

\begin{tabular}{ccccc}
\hline$U_{c}\left[\mathrm{~m} . \mathrm{s}^{-1}\right]$ & $1 \mathrm{bar}$ & $2 \mathrm{bar}$ & 6 bar & 7 bar \\
\hline Methane & $0.60=1.8 S_{L}$ & $0.60=2.5 S_{L}[22]$ & $0.37=2.7 S_{L}[22]$ & $0.30=2.3 S_{L}$ \\
Ethane & $0.60=1.6 S_{L}$ & N/A & $0.60=2.8 S_{L}$ & N/A \\
Ethylene & $1.50=2.1 S_{L}[10]$ & N/A & N/A & N/A \\
Propane & $0.80=2.0 S_{L}[10]$ & N/A & N/A & N/A \\
\hline
\end{tabular}




\subsection{Extension to co-flow configurations}

Figure 8 plots the dimensionless lift-off height as a function of the dimensionless bulk jet velocity following Kalghatgi's model (Eq. (1)). Results shown in Fig. 8 exclude those for which the co-flow velocity exceeds the threshold value defined by Tab. 1 and also include data from [22], recorded for methane and a larger fuel tube. It is evident that all the slopes feature a value close to unity (see dashed line), which confirms the good performance of Kalghatgi's model. However, it is obvious that the collapse of the data is poor and this is attributed to the presence of a co-flow that is not accounted for in Eq. (1). The objective of this section is then to develop a corrective term that should be added to Kalghatgi's model to capture co-flow effects and collapse all the data onto a single line defined by the dashed line in Fig. 8a.

By analogy with [24-26], an effective velocity is defined here and is expressed as a function of the bulk jet velocity as follows: $U_{e f f}=U_{j}+U_{0}$. At this stage, the expression of $U_{0}$ is not provided but its numerical value can be obtained, for each fuel-pressure-co-flow velocity trio, by fitting the available data to the line of unity slope and zero Y-intercept (dashed line in Fig. 8a). This is shown in Fig. 8b. Note that the value of $U_{0}$ changes when fuel, pressure, or co-flow velocity are changed. 

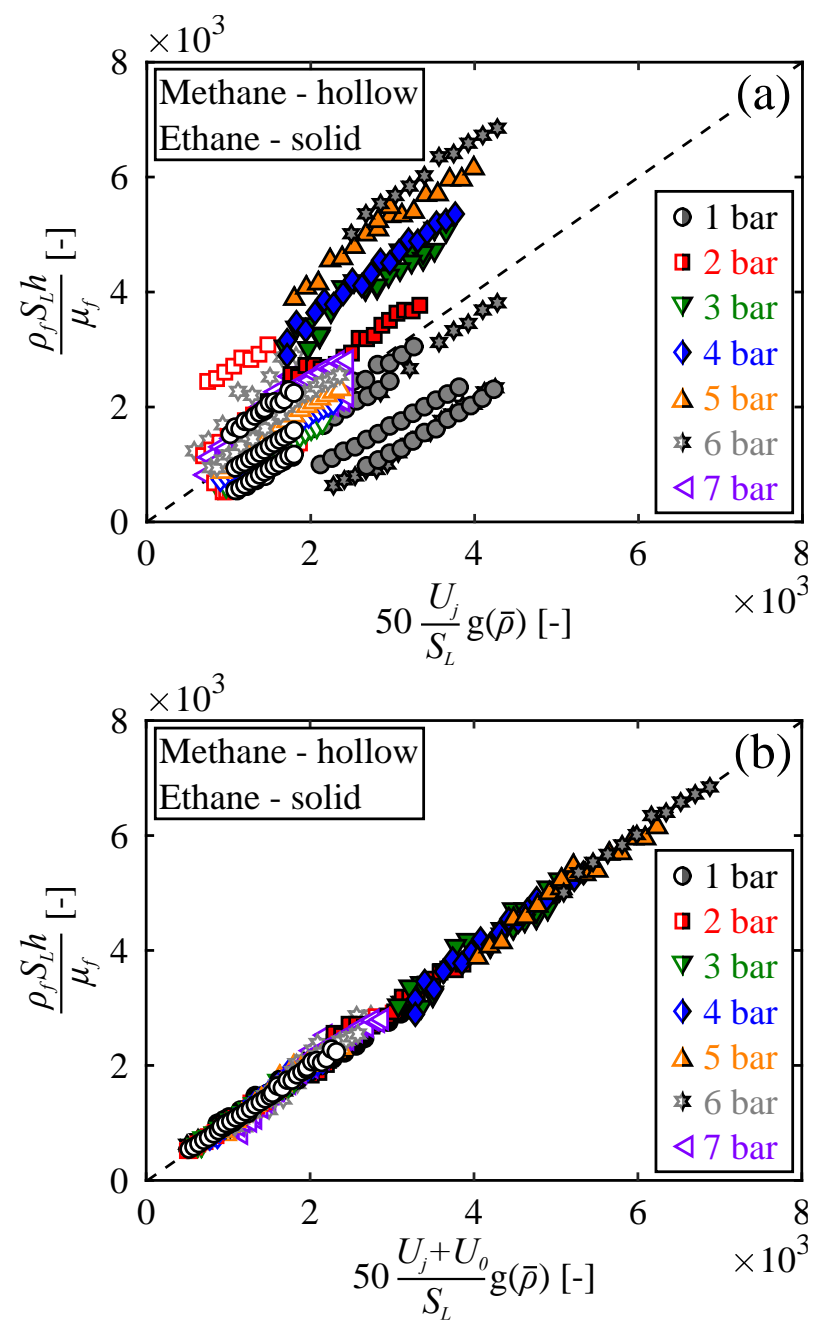

Fig. 8: (a) Dimensionless lift-off height as a function of the dimensionless bulk jet velocity for all the conditions reported in Figs. 5 and 6 that also meet the criteria that $\kappa$ is not a function of $U_{c}$. (b) Same but with an additional term $U_{0}$ tailored to yield a zero $\mathrm{Y}$-intercept.

Values of $U_{0}$ found for methane with $U_{c}=0.30 \mathrm{~m} \cdot \mathrm{s}^{-1}$ (black circles for present data $(D=3.4 \mathrm{~mm})$ and black stars for data from [22] $(D=4.6 \mathrm{~mm})$ and ethane with $U_{c}=0.60 \mathrm{~m} \cdot \mathrm{s}^{-1}$ (orange diamonds) are plotted as a function of pressure in Fig. 9. The following observation can be made:

- Regardless of the fuel, $U_{0}$ increases with pressure. This increase does not seem to be linear due to a slight inflection around $P=1$ bar. However, a linear fit of the data would remain within error bars.

- The velocity $U_{0}$ is larger for ethane than for methane and this is likely to be attributed to the larger co-flow velocity.

- Discrepancies between values obtained for the present data $(D=3.4 \mathrm{~mm})$ and previous data $(D=4.6 \mathrm{~mm})[22]$ lie within the confidence range, suggesting that the fuel tube inner diameter and wall thickness do not have a significant influence on the effective velocity.

- For methane, negative values of $U_{0}$ are found if $P<6$ bar. 


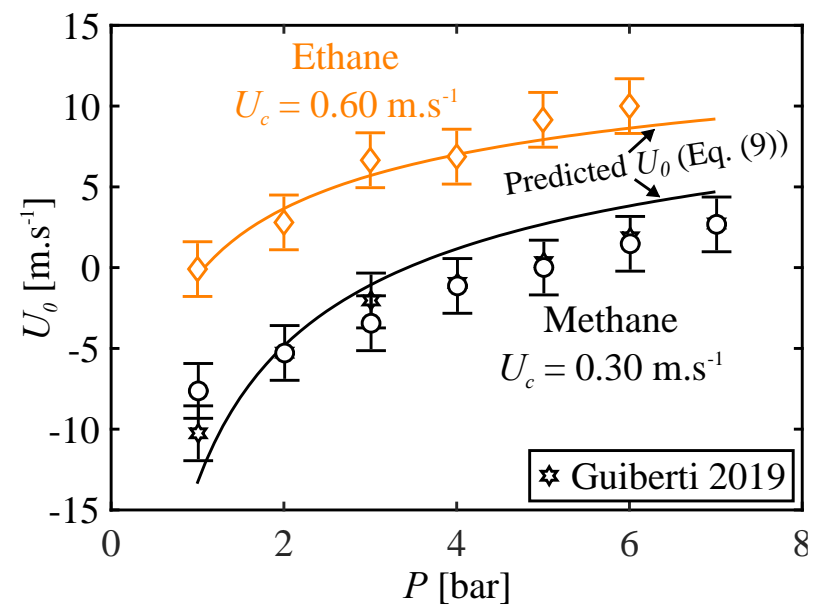

Fig. 9: $U_{0}$ as a function of pressure for methane with $U_{c}=0.30 \mathrm{~m} . \mathrm{s}^{-1}$ and ethane with $U_{c}=0.60 \mathrm{~m} . \mathrm{s}^{-1}$. Symbols and lines show measured and predicted values (using Eq. (9)), respectively.

Figure 10 shows $U_{0}$ as a function of the co-flow velocity for different pressures for methane (Fig. 10a) and ethane (Fig. 10b). Regardless of fuel and pressure, $U_{0}$ increases with the co-flow velocity. In addition, $U_{0}$ increases with pressure and this is compatible with Fig. 9. Globally, for the same pressure and co-flow velocity, $U_{0}$ is larger for methane than for ethane. Findings of Figs. 9 and 10 are compatible with an expression for the effective velocity that would combine features of Eqs. (2), (4), and (5) as follows $U_{e f f}=U_{j}+\mathrm{A} U_{c}-\mathrm{B} S_{L}$, where A and B take values that depend on fuel, and effects of pressure are through the laminar burning velocity. Therefore, the following expression is proposed for the effective velocity:

$$
U_{e f f}=U_{j}+\frac{1.5\left(\frac{\rho_{o}}{\rho_{f}}\right)^{\frac{1}{2}}\left(U_{c}-\beta S_{L}\right)}{\mathrm{Sc}_{\mathrm{t}} \mathrm{Z}_{\mathrm{st}}}
$$

Where $\mathrm{Sc}_{\mathrm{t}}$ stands for a turbulent Schmidt number and $\beta$ is a constant. Introduction of a turbulent Schmidt number allows accounting for different spread rates of velocity and species. The coefficient 1.5 in front of the density term is added for consistency with [56]. The coefficient $\beta$ multiplies the laminar burning velocity because the actual flame base propagation velocity along the stoichiometric contour is an edge-flame speed, that was shown to be close but not necessarily strictly equal to the laminar burning velocity $[11,22]$. 

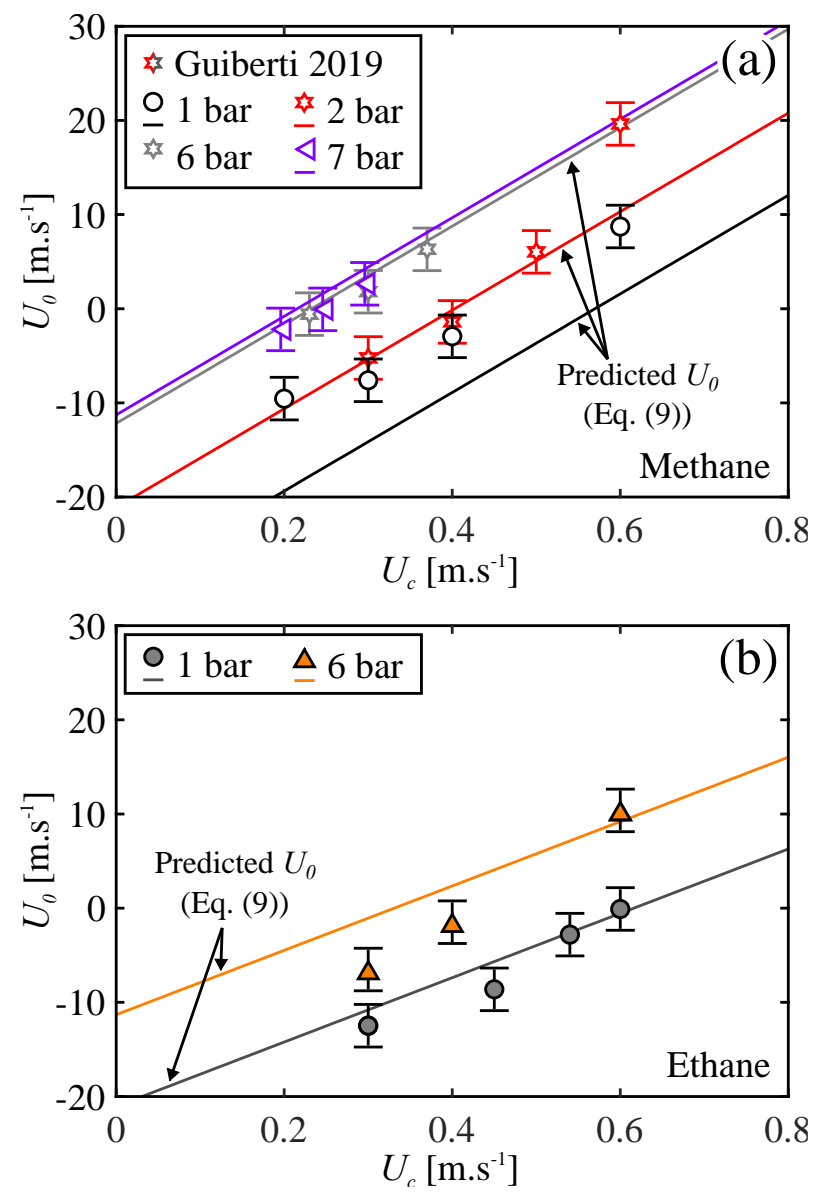

Fig. 10: $U_{0}$ as a function of co-flow velocity for methane (a) and ethane (b) and a range of pressures. Symbols and lines show measured and predicted values, respectively.

The definition of the effective velocity given by Eq. (8) is now tested against the data presented in Figs. 5 and 6 as well as data from the literature [10, 11, 22, 27]. This is shown in Fig. 11 that plots the measured lift-off height as a function of the effective velocity for a range of fuels, co-flow velocities, pressures, and burner dimensions. For each fuel-pressure-burner configuration trio, values of $\mathrm{Sc}_{\mathrm{t}}$ and $\beta$ providing the best fit of the data are used, which allows accounting for the dependency of the turbulent Schmidt number and edge-flame speed to each specific configuration. Figure 11 shows that an effective velocity that depends on the co-flow velocity, the stoichiometric mixture fraction, the laminar flame speed, the oxidizer to fuel density ratio, and a turbulent Schmidt number provides a good collapse of the lift-off data. Worst performances are obtained with the data of [27], for methane at $P=1$ bar and their largest fuel nozzle $(D=5.0 \mathrm{~mm})$, with a coefficient of determination equal to $\mathrm{R}^{2}=0.91$. This behavior may be attributed to the rather large co-flow velocity considered in this case $U_{c}=0.64 \mathrm{~m} \cdot \mathrm{s}^{-1}$. Indeed, data from Brown et al. [10] showed that for methane and $P=1$ bar, linearity between lift-off height and co-flow velocity is lost if $U_{c}>0.45 \mathrm{~m} . \mathrm{s}^{-1}$. Similar behavior was observed in [10] for propane if $U_{c}>0.80 \mathrm{~m} . \mathrm{s}^{-1}$ and ethylene if $U_{c}>2.0 \mathrm{~m} \cdot \mathrm{s}^{-1}$. This suggests that there is a critical co-flow velocity, which is a function of the fuel, above which the definition of an effective velocity following Eq. (8) ceases to be valid. 

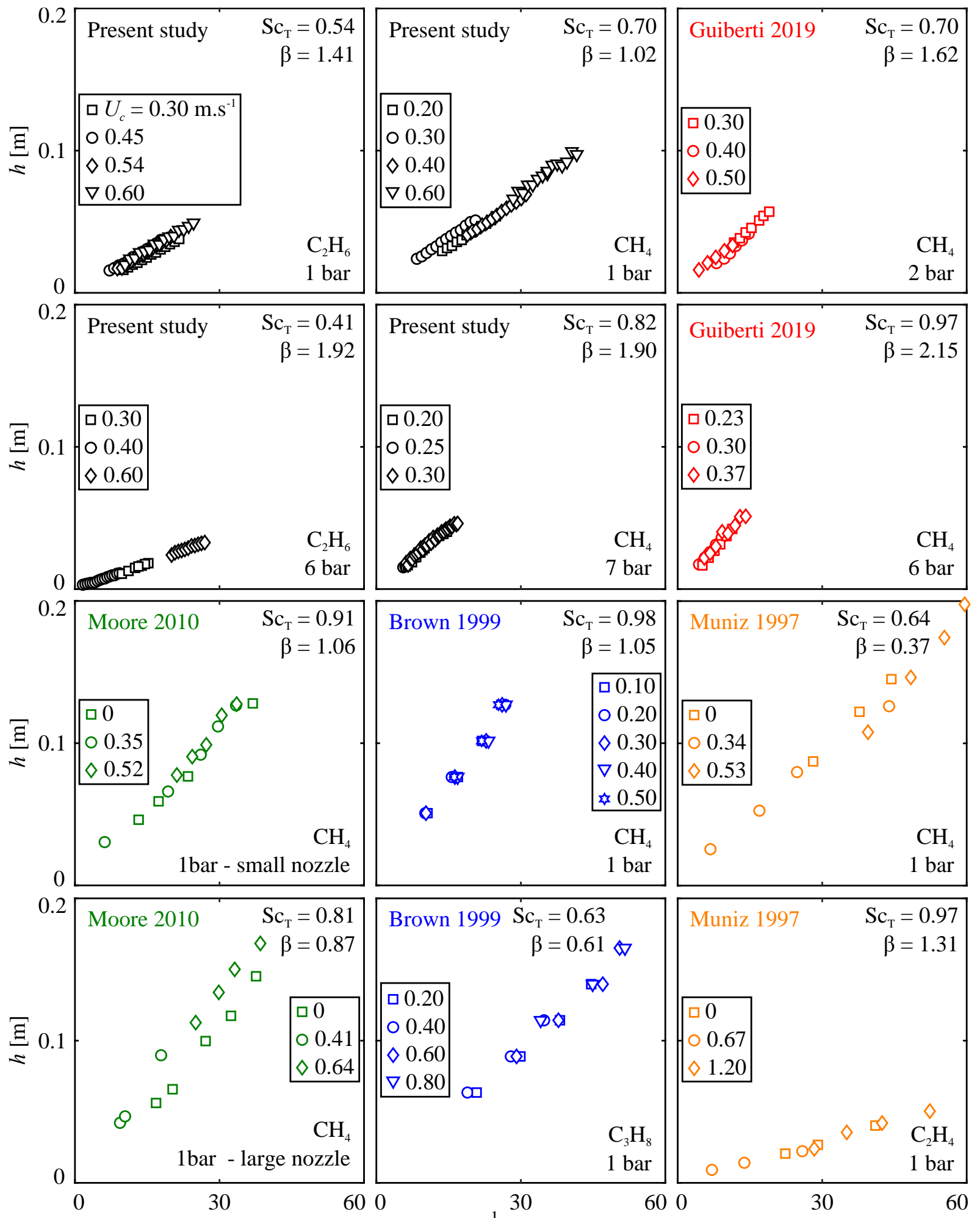

$$
6000 \frac{1.5\left(\frac{\rho_{o}}{\rho_{f}}\right)^{\frac{1}{2}}{ }^{30}\left(U_{c}-\beta S_{L}\right)}{\mathrm{Sc}_{\mathrm{t}} Z_{\mathrm{st}}}\left[\mathrm{m} . \mathrm{s}^{-1}\right]
$$

Fig. 11: Measured lift-off height as a function of the effective velocity for a range of fuels, co-flow velocities, pressures, and burner dimensions.

The turbulent Schmidt numbers yielding a good collapse of the data range from $\mathrm{Sc}_{\mathrm{t}}=0.41$ to $\mathrm{Sc}_{\mathrm{t}}=0.98$, with an average value of $\mathrm{Sc}_{\mathrm{t}}=0.75$. These values are within the range of Schmidt numbers typical encountered in turbulent flows [57] and the average value is close to that often used in turbulent 
jet flow and combustion modeling $\mathrm{Sc}_{\mathrm{t}}=0.70$ [58-60]. Values of $\beta$ range from $\beta=0.37$ to $\beta=2.15$, with $\beta=1.24$ on average. Again, this is compatible with typical values of the edge-flame speed that are comprised between 0 and $3 S_{L}[11,22]$ and are found equal to $1.5 S_{L}$ in [61]. The variability of $\mathrm{Sc}_{\mathrm{t}}$ and $\beta$ observed here may be also partly attributed to experimental uncertainties. In an effort to provide a model with predictive capabilities that do not require calibration, values $S_{\mathrm{t}}=0.70$ and $\beta=1.50$ are retained. These values are statistically representative of the available data and are physically meaningful $[59,61]$.

Figures 9 and 10 show predicted values of $U_{0}$ (solid lines) if these are computed as follows:

$$
U_{0}=\frac{1.5\left(\frac{\rho_{o}}{\rho_{f}}\right)^{\frac{1}{2}}\left(U_{c}-1.5 S_{L}\right)}{0.7 \mathrm{Z}_{\mathrm{st}}}
$$

Predictions from Eq. (9) are in good agreement with measured values except for methane at $P=1$ bar and ethane at $P=6$ bar for $U_{c}=0.30 \mathrm{~m}_{\mathrm{s}} \mathrm{s}^{-1}$. Reasons of this mismatch for methane are not clear but the mismatch for ethane can be attributed to the small co-flow velocity that does not allow the flame base to stabilize away from the flow development region (see Fig. $4 \mathrm{~b}$ ), where many of the assumptions required to construct Kalghatgi's model are not satisfied.

Figure 12 plots the dimensionless lift-off height as a function of the dimensionless effective velocity computed with Eq. (8) and $\mathrm{Sc}_{\mathrm{t}}=0.70$ and $\beta=1.50$ for the same data used in Fig. 8. There is a good collapse of all the lift-off data on the unity slope and zero Y-intercept curve. This confirms that Kalghatgi's model augmented with a term designed to account for effects of the co-flow yields good

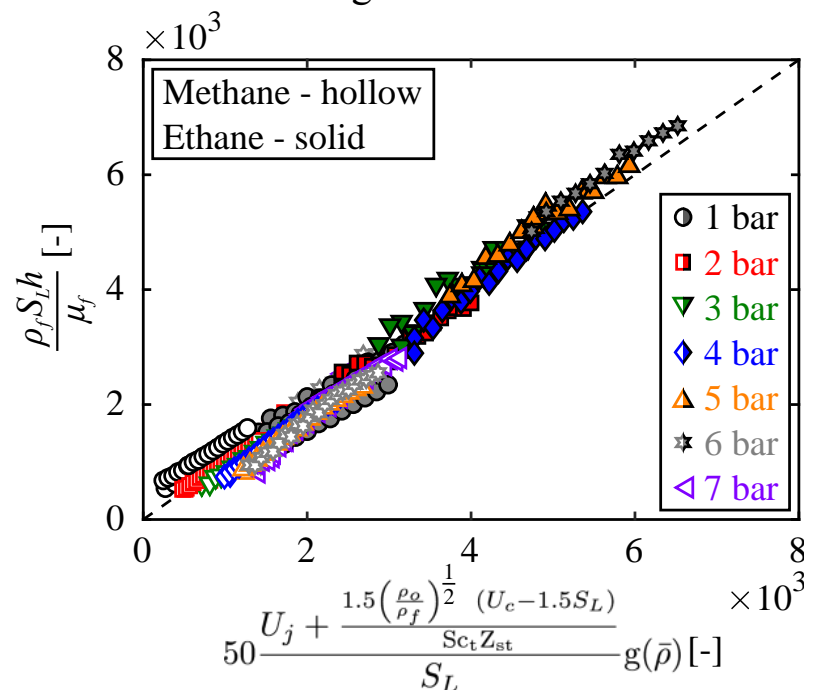

Fig. 12: Dimensionless lift-off height as a function of the dimensionless effective velocity for all the conditions reported in Fig. 8. 
results and this has been verified for two fuels, two fuel tube diameters, and wide ranges of pressure and co-flow velocity.

\subsection{Discussion}

Figure 11 shows that there are large variations of the value of $\beta$ providing the best collapse of the liftoff data and that those depend on the burner configuration and fuel. Careful examination of the distribution of $\beta$ shows that, on average, values of $\beta$ for the data recorded by the authors at atmospheric and elevated pressure, in the present study and in [22], are larger $(\beta=1.62)$ than that obtained from the literature data available at atmospheric pressure $(\beta=0.85)$. On average, lifted flames reported here and in [22] sit closer to the nozzle than that observed in [10, 11, 27, 33]. While it can be argued that large variations of turbulent Schmidt number are expected when the configuration is changed [57], there is limited physical ground justifying such large variations of $\beta$, which are synonymous with large variations of the ratio of the edge-flame speed to the laminar burning velocity. Variations of $\beta$ with burner configuration, fuel, and/or pressure may be partly attributed to variations in the degree of stratification immediately upstream of the edge-flame, which could affect its propagation speed.

Another possible explanation is that Kalghatgi's model, even augmented with an effective velocity, does not account for the jet virtual origin. Previous work has shown that, to improve predictions of the velocity field, it is useful to correct the axial distance from the nozzle exit by adding to it the distance from the nozzle exit to the virtual origin $h_{0}$ [56]. The schematic of Fig. 13a shows the structure of two concentric jets in the near-field. Important features include the length of the potential core, the half jet width (defined at each axial location as the distance from the centerline to the location where the local mean velocity is equal to half of the mean centerline velocity), which is a measure of the jet spreading rate, and the position of the virtual origin (location of the intersection of the extrapolated jet contour and the centerline).

The virtual origin is not considered in Kalghatgi's model. As a consequence, the further the virtual origin is from the nozzle exit, the poorer are Kalghatgi's model predictions. Therefore, if the presence of a co-flow modifies the location of the virtual origin, the flame lift-off height changes but this effect is not captured by Kalghatgi's model, even augmented with an effective velocity. Schematics of Fig. 13a-b show that two jets with different spreading rates, indicative of different mixing efficiencies, typically feature different virtual origins. This was demonstrated experimentally in [62]. Because the presence of a co-flow influences the jet spreading rate through density, velocity, and Reynolds number effects [32, 63-67], it is clear that the presence of a co-flow displaces the virtual origin, the extent of which is a function of the co-flow velocity and density. This is confirmed by works of Chu et al. [64] 
and Uddin and Pollard [66]. Figure 13c shows the structure of two concentric jets if a recirculation zone exists in the wake of the nozzle. In such a case, mixing is retarded and the virtual origin shifts downstream [66]. In some cases, this phenomenon has been shown to yield virtual origin located downstream of the nozzle exit [63].

(a) Small spreading rate

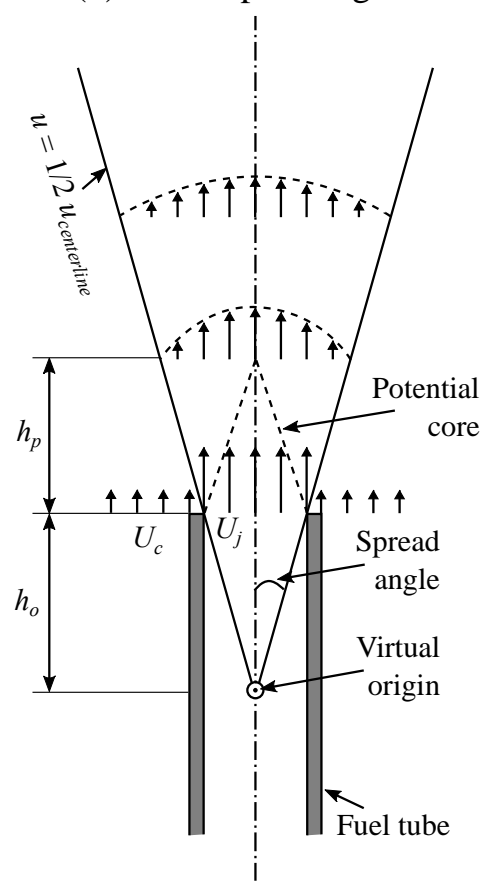

(b) Large spreading rate

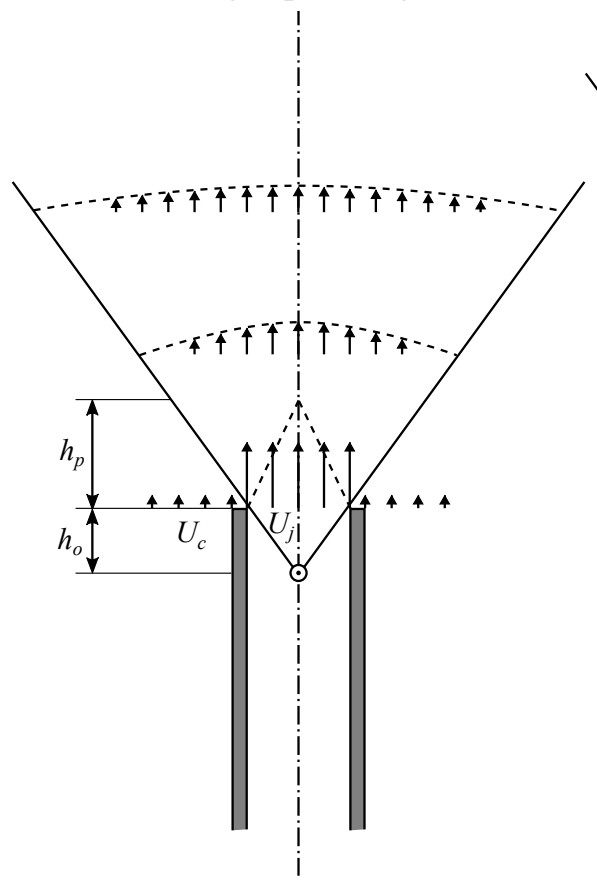

(c) With recirculation zone

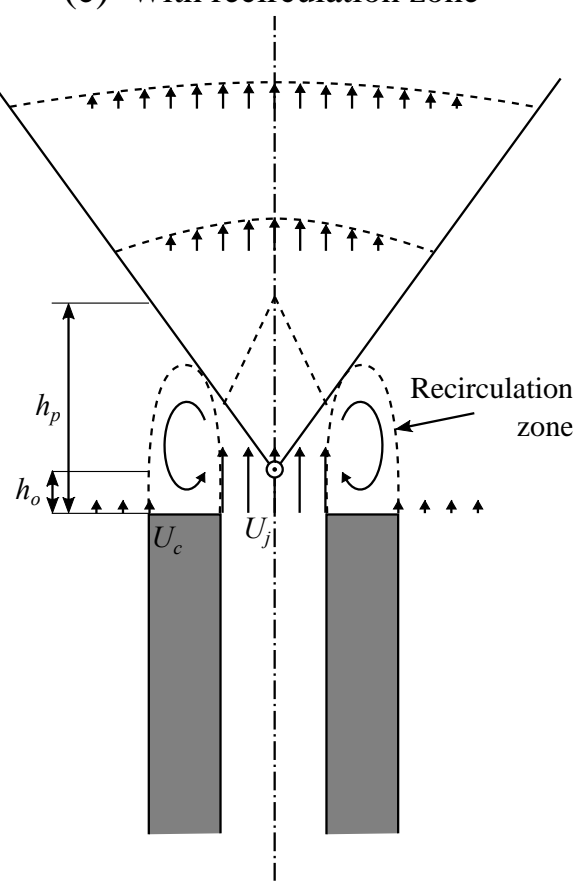

Fig. 13: Schematics showing the structure of two concentric jets featuring different spreading rates or a recirculation zone.

The minimum value found for $\beta$ in Fig. 11 is $\beta=0.37$ for the data of Muñiz and Mungal [11] with methane at $P=1$ bar. The maximum value is $\beta=2.15$ for the data of Guiberti et al. [22] with methane at $P=6$ bar. Both cases feature the same fuel and a similar co-flow velocity range but the dimensions of the burner and the pressure are different. Based on [32, 63-67], pressure is not expected to enhance significantly effects of the co-flow, except indirectly through the Reynolds number. The fuel tube inner diameter is close to $D=4.6 \mathrm{~mm}$ in both cases but the outer diameters are $6.4 \mathrm{~mm}$ and $9.5 \mathrm{~mm}$ in [22] and [11], respectively. This leads to very different nozzle wall thicknesses of $0.9 \mathrm{~mm}$ and $2.4 \mathrm{~mm}$, respectively. It can then be argued that a recirculation zone may be produced in the wake of the rather thick nozzle wall in [11] but not in [22]. Therefore, both cases could feature very different virtual origin locations which could explain, at least partly, why flames of [11] are stabilized further away from the nozzle than that of [22] even for the same fuel, co-flow velocity, and pressure. It is then possible that large variations of nozzle dimensions require slight adjustments of the parameters $\beta$ and $\mathrm{Sc}_{\mathrm{t}}$ of the model presented in Eq. (8).

Furthermore, due to the thermal power limitation of the HPCD, the bulk jet velocities examined in the present study and in [22] are smaller than that typically used in [10, 11, 27, 33]. In addition, the co- 
flow nozzle used in the present study and in [22] is larger than that used in [10, 27,33]. This translates into different co-flow Reynolds numbers $\mathrm{Re}_{\mathrm{c}}$ and different co-flow Reynolds number to jet Reynolds number ratios $\operatorname{Re}_{\mathrm{c}} / \mathrm{Re}_{\mathrm{j}}$, as shown in Fig. 14. Most of the data taken from the literature feature laminar, transitional, or slightly turbulent co-flows while the co-flow is always turbulent in the present study and in [22], with Reynolds numbers up to $\operatorname{Re}_{\mathrm{c}}=60,200$. In addition, the co-flow Reynolds number to jet Reynolds number ratio is globally smaller than unity for the data of $[10,11,27]$ while it is almost always larger than unity for the present study and in [22]. In comparison to free jets, the presence of a laminar co-flow was shown to stabilize the shear layer, due to reduced shear, and slow down mixing [64-67]. However, it can be argued that if the co-flow has a Reynolds number larger than that of the jet, the presence of the co-flow may destabilize the shear layer and promote mixing [31]. This may explain why lifted flames examined here or in [22] for $P=1$ bar and co-flow velocities up to $U_{c}=0.20 \mathrm{~m} \cdot \mathrm{s}^{-1}$ sit closer to the nozzle than those stabilized without a co-flow in $[11,27]$.

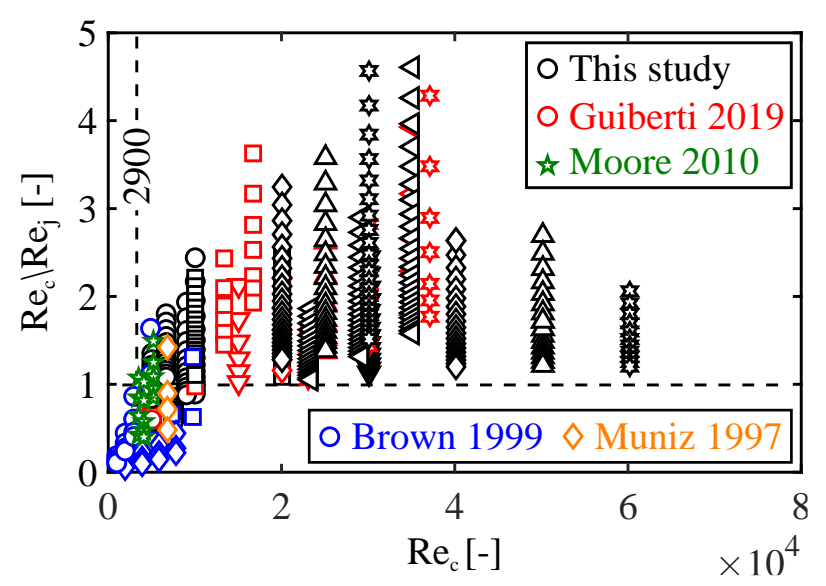

Fig. 14: $\operatorname{Re}_{\mathrm{c}} / \mathrm{Re}_{\mathrm{j}}$ as a function $\operatorname{Re}_{\mathrm{c}}$ for all the data examined in this study and in Fig. 11.

All of the above may explain why a range of different values of $\beta$ are found in Fig. 11. Such differences are expected given that the correlation is, in its core, rather empirical. This, however should not take anything away from its usefulness not only in characterizing a broad range of lifted flames but also in providing a much-improved understanding of the mechanism of stabilization. Further improvement of this correlation may be made by including the virtual origin in the formulation. This, however, is beyond the scope of this paper.

\section{Conclusions}

This paper reported an experimental investigation of the effects of elevated pressures and co-flow on the lift-off behavior of non-premixed turbulent jet flames. The results were first interpreted based on Kalghatgi's model, which was then extended to account for effects of the co-flow. The main findings are: 
- Kalghatgi's model is able to predict accurately the slope of the lift-off height $v s$ bulk jet velocity curves even in the presence of a co-flow, as long as the co-flow velocity does not exceed a critical value close to 1.5 to 2 times the laminar burning velocity. This has been verified for methane and ethane fuels, pressures up to 7 bar, and jet Reynolds numbers up to $\operatorname{Re}=57,500$.

- Extending Kalghatgi's model by replacing the bulk jet velocity with an effective velocity allows predicting effects of the co-flow on the lift-off height. The proposed effective velocity depends on co-flow velocity, the stoichiometric mixture fraction, the laminar flame speed, the oxidizer to fuel density ratio, and a turbulent Schmidt number. Such expression for the effective velocity is not applicable for co-flow velocities larger that a critical value, also close to 1.5 to 2 times the laminar burning velocity.

- The proposed effective velocity includes a term that explains why the Y-intercept of the liftoff height $v s$ bulk jet velocity curves is often negative for zero or low co-flow velocities. This behavior cannot be predicted by Kalghatgi's original model and is usually not discussed, or hidden.

- The complexity of the shear layer dynamics between a turbulent central jet and an annular coflow is such that there are additional parameters, such as the location of the virtual origin, that may play an important role in the flame lift-off and these are not accounted for in the proposed model. At this stage, it is not clear how exactly the model could be improved or if it is even possible to come up with a general expression that is valid for any configuration.

\section{Acknowledgements}

The research reported in this publication was supported by funding from King Abdullah University of Science and Technology (KAUST). 


\section{References}

[1] F. Zhao, M.C. Lai, D.L. Harrington, Automotive spark-ignited direct-injection gasoline engines, Prog. Energy Combust. Sci. 25(5) (1999) 437-562.

[2] M. Yao, Z. Zheng, H. Liu, Progress and recent trends in homogeneous charge compression ignition (HCCI) engines, Prog. Energy Combust. Sci. 35(5) (2009) 398-437.

[3] L.Y.M. Gicquel, G. Staffelbach, T. Poinsot, Large Eddy Simulations of gaseous flames in gas turbine combustion chambers, Prog. Energy Combust. Sci. 38(6) (2012) 782-817.

[4] L. Vanquickenborne, A. Van Tiggelen, The stabilization mechanism of lifted diffusion flames, Combust. Flame 10(1) (1966) 59-69.

[5] B.J. Lee, J.S. Kim, S.H. Chung, Effect of dilution on the liftoff of non-premixed jet flames, Symp. (Int.) Combust. 25(1) (1994) 1175-1181.

[6] R.W. Schefer, P.J. Goix, Mechanism of flame stabilization in turbulent, lifted-jet flames, Combust. Flame 112(4) (1998) 559-574.

[7] S.R. Tieszen, D.W. Stamps, T.J. O'hern, A heuristic model of turbulent mixing applied to blowout of turbulent jet diffusion flames, Combust. Flame 106(4) (1996) 442-466.

[8] D. Bradley, P.H. Gaskell, X. Gu, A. Palacios, Jet flame heights, lift-off distances, and mean flame surface density for extensive ranges of fuels and flow rates, Combust. Flame 164 (2016) 400409.

[9] S. Lamige, J. Min, C. Galizzi, F. André, F. Baillot, D. Escudié, K.M. Lyons, On preheating and dilution effects in non-premixed jet flame stabilization, Combust. Flame 160(6) (2013) 11021111.

[10] C.D. Brown, K.A. Watson, K.M. Lyons, Studies on lifted jet flames in coflow: The stabilization mechanism in the near- and far-fields, Flow Turbul. Combust. 62(3) (1999) 249-273.

[11] L. Muñiz, M.G. Mungal, Instantaneous flame-stabilization velocities in lifted-jet diffusion flames, Combust. Flame 111(1) (1997) 16-31.

[12] S.D. Terry, K.M. Lyons, Low Reynolds number turbulent lifted flames in high co-flow, Combust. Sci. Technol. 177(11) (2005) 2091-2112. 
[13] K.A. Watson, K.M. Lyons, J.M. Donbar, C.D. Carter, Simultaneous Rayleigh imaging and CHPLIF measurements in a lifted jet diffusion flame, Combust. Flame 123(1) (2000) 252-265.

[14] C.J. Lawn, Lifted flames on fuel jets in co-flowing air, Prog. Energy Combust. Sci. 35(1) (2009) 1-30.

[15] G.T. Kalghatgi, Lift-off heights and visible lengths of vertical turbulent jet diffusion flames in still air, Combust. Sci. Technol. 41(1-2) (1984) 17-29.

[16] N. Peters, F.A. Williams, Liftoff characteristics of turbulent jet diffusion flames, AIAA Journal 21(3) (1983) 423-429.

[17] R.C. Miake-Lye, J.A. Hammer, Lifted turbulent jet flames: A stability criterion based on the jet large-scale structure, Symp. (Int.) Combust. 22(1) (1989) 817-824.

[18] J.E. Broadwell, W.J.A. Dahm, M.G. Mungal, Blowout of turbulent diffusion flames, Symp. (Int.) Combust. 20(1) (1985) 303-310.

[19] J. Buckmaster, Edge-flames, J. Eng. Math. 31(2) (1997) 269-284.

[20] Q. Wang, L. Hu, M. Zhang, F. Tang, X. Zhang, S. Lu, Lift-off of jet diffusion flame in subatmospheric pressures: An experimental investigation and interpretation based on laminar flame speed, Combust. Flame 161(4) (2014) 1125-1130.

[21] S. Bang, B.J. Lee, S.H. Chung, Effect of pressure on the characteristics of lifted flames, Proc. Combust. Inst. 37(2) (2019) 2013-2020.

[22] T.F. Guiberti, W.R. Boyette, W.L. Roberts, A.R. Masri, Pressure effects and transition in the stabilization mechanism of turbulent lifted flames, Proc. Combust. Inst. 37(2) (2019) 21672174.

[23] S. Karami, E.R. Hawkes, M. Talei, J.H. Chen, Mechanisms of flame stabilisation at low lifted height in a turbulent lifted slot-jet flame, J. Fluid Mech. 777 (2015) 633-689.

[24] D. Han, M.G. Mungal, Simultaneous measurements of velocity and CH distributions. Part 1: jet flames in co-flow, Combust. Flame 132(3) (2003) 565-590.

[25] C.J. Montgomery, C.R. Kaplan, E.S. Oran, The effect of coflow velocity on a lifted methane-air jet diffusion flame, Symp. (Int.) Combust. 27(1) (1998) 1175-1182. 
[26] S. Kumar, P.J. Paul, H.S. Mukunda, Prediction of flame liftoff height of diffusion/partially premixed jet flames and modeling of mild combustion burners, Combust. Sci. Technol. 179(10) (2007) 2219-2253.

[27] N.J. Moore, K.M. Lyons, Leading-edge flame fluctuations in lifted turbulent flames, Combust. Sci. Technol. 182(7) (2010) 777-793.

[28] F.P. Ricou, D.B. Spalding, Measurements of entrainment by axisymmetrical turbulent jets, J. Fluid Mech. 11(1) (1961) 21-32.

[29] W.J.A. Dahm, C.E. Frieler, G. Tryggvason, Vortex structure and dynamics in the near field of a coaxial jet, J. Fluid Mech. 241 (1992) 371-402.

[30] H. Rehab, E. Villermaux, E.J. Hopfinger, Flow regimes of large-velocity-ratio coaxial jets, J. Fluid Mech. 345 (1997) 357-381.

[31] G. Balarac, O. Métais, M. Lesieur, Mixing enhancement in coaxial jets through inflow forcing: A numerical study, Phys. Fluids 19(7) (2007) 075102.

[32] G.L. Brown, A. Roshko, On density effects and large structure in turbulent mixing layers, J. Fluid Mech. 64(4) (1974) 775-816.

[33] A. Joedicke, N. Peters, M. Mansour, The stabilization mechanism and structure of turbulent hydrocarbon lifted flames, Proc. Combust. Inst. 30(1) (2005) 901-909.

[34] Y. Nada, K. Matsumoto, S. Noda, Liftoff heights of turbulent non-premixed flames in co-flows diluted by $\mathrm{CO}_{2} / \mathrm{N}_{2}$, Combust. Flame 161(11) (2014) 2890-2903.

[35] J. Min, F. Baillot, Experimental investigation of the flame extinction processes of nonpremixed methane flames inside an air coflow diluted with $\mathrm{CO}_{2}, \mathrm{~N}_{2}$, or Ar, Combust. Flame 159(12) (2012) 3502-3517.

[36] A. Upatnieks, J.F. Driscoll, C.C. Rasmussen, S.L. Ceccio, Liftoff of turbulent jet flamesassessment of edge flame and other concepts using cinema-PIV, Combust. Flame 138(3) (2004) 259-272.

[37] W.R. Boyette, T.F. Guiberti, G. Magnotti, W.L. Roberts, Structure of turbulent nonpremixed syngas flames at high pressure, Proc. Combust. Inst. 37(2) (2019) 2207-2214. 
[38] N. Otsu, A threshold selection method from gray-level histograms, IEEE Trans. Syst. Man Cybern. 9(1) (1979) 62-66.

[39] A. Cessou, C. Maurey, D. Stepowski, Parametric and statistical investigation of the behavior of a lifted flame over a turbulent free-jet structure, Combust. Flame 137(4) (2004) 458-477.

[40] C.M. Or, K.M. Lam, P. Liu, Potential core lengths of round jets in stagnant and moving environments, J. Hydro-Environ. Res. 5(2) (2011) 81-91.

[41] F.N. Egolfopoulos, P. Cho, C.K. Law, Laminar flame speeds of methane-air mixtures under reduced and elevated pressures, Combust. Flame 76(3) (1989) 375-391.

[42] G. Rozenchan, D.L. Zhu, C.K. Law, S.D. Tse, Outward propagation, burning velocities, and chemical effects of methane flames up to 60 ATM, Proc. Combust. Inst. 29(2) (2002) 14611470.

[43] F. Halter, C. Chauveau, N. Djebaïli-Chaumeix, I. Gökalp, Characterization of the effects of pressure and hydrogen concentration on laminar burning velocities of methane-hydrogen-air mixtures, Proc. Combust. Inst. 30(1) (2005) 201-208.

[44] W. Lowry, J. De Vries, M. Krejci, E. Petersen, Z. Serinyel, W. Metcalfe, H. Curran, G. Bourque, Laminar flame speed measurements and modeling of pure alkanes and alkane blends at elevated pressures, J. Eng. Gas Turbines Power 133(9) (2011) 091501-091501-091509.

[45] Y. Kochar, J. Seitzman, T. Lieuwen, W. Metcalfe, S.A. Burke, H. Curran, M. Krejci, W. Lowry, E. Petersen, G. Bourque, Laminar flame speed measurements and modeling of alkane blends at elevated pressures with various diluents, Proceedings of the ASME Turbo Expo (June 6-10, 2011) $129-140$.

[46] Reaction Design: San Diego, CHEMKIN-PRO 15131, (2013).

[47] H. Wang, X. You, A.V. Joshi, S.G. Davis, A. Laskin, F.N. Egolfopoulos, C.K. Law, USC Mech Version II. High-temperature combustion reaction model of $\mathrm{H}_{2} / \mathrm{CO} / \mathrm{C} 1-\mathrm{C} 4$ compounds, (Last accessed: September 2018), Available from: http://ignis.usc.edu/USC_Mech_II.htm.

[48] F.N. Egolfopoulos, C.K. Law, Chain mechanisms in the overall reaction orders in laminar flame propagation, Combust. Flame 80(1) (1990) 7-16. 
[49] F.N. Egolfopoulos, D.L. Zhu, C.K. Law, Experimental and numerical determination of laminar flame speeds: Mixtures of $\mathrm{C}_{2}$-hydrocarbons with oxygen and nitrogen, Symp. (Int.) Combust. 23(1) (1991) 471-478.

[50] M.I. Hassan, K.T. Aung, O.C. Kwon, G.M. Faeth, Properties of laminar premixed hydrocarbon/air flames at various pressures, J. Propul. Power 14(4) (1998) 479-488.

[51] C.M. Vagelopoulos, F.N. Egolfopoulos, Direct experimental determination of laminar flame speeds, Symp. (Int.) Combust. 27(1) (1998) 513-519.

[52] G. Jomaas, X.L. Zheng, D.L. Zhu, C.K. Law, Experimental determination of counterflow ignition temperatures and laminar flame speeds of $\mathrm{C}_{2}-\mathrm{C}_{3}$ hydrocarbons at atmospheric and elevated pressures, Proc. Combust. Inst. 30(1) (2005) 193-200.

[53] O. Park, P.S. Veloo, F.N. Egolfopoulos, Flame studies of $\mathrm{C}_{2}$ hydrocarbons, Proc. Combust. Inst. 34(1) (2013) 711-718.

[54] M. Goswami, R.J.M. Bastiaans, L.P.H. De Goey, A.A. Konnov, Experimental and modelling study of the effect of elevated pressure on ethane and propane flames, Fuel 166 (2016) 410418.

[55] M. Mitu, D. Razus, V. Giurcan, D. Oancea, Experimental and numerical study of laminar burning velocity of ethane-air mixtures of variable initial composition, temperature and pressure, Energy Fuels 28(3) (2014) 2179-2188.

[56] J. Lee, S.H. Won, S.H. Jin, S.H. Chung, Lifted flames in laminar jets of propane in coflow air, Combust. Flame 135(4) (2003) 449-462.

[57] C. Gualtieri, A. Angeloudis, F. Bombardelli, S. Jha, T. Stoesser, On the values for the turbulent Schmidt number in environmental flows, Fluids 2(2) (2017).

[58] D.B. Spalding, Concentration fluctuations in a round turbulent free jet, Chem. Eng. Sci. 26(1) (1971) 95-107.

[59] X.-S. Bai, L. Fuchs, Sensitivity study of turbulent reacting flow modeling in gas turbine combustors, AIAA Journal 33(10) (1995) 1857-1864. 
[60] C.L. Lubbers, G. Brethouwer, B.J. Boersma, Simulation of the mixing of a passive scalar in a round turbulent jet, Fluid Dyn. Res. 28(3) (2001) 189.

[61] J. Lee, S.H. Won, S.H. Jin, S.H. Chung, O. Fujita, K. Ito, Propagation speed of tribrachial (triple) flame of propane in laminar jets under normal and micro gravity conditions, Combust. Flame 134(4) (2003) 411-420.

[62] N.E. Kotsovinos, A note on the spreading rate and virtual origin of a plane turbulent jet, J. Fluid Mech. 77(2) (1976) 305-311.

[63] T.G. Malmström, A.T. Kirkpatrick, B. Christensen, K.D. Knappmiller, Centreline velocity decay measurements in low-velocity axisymmetric jets, J. Fluid Mech. 346 (1997) 363-377.

[64] P.C.K. Chu, J.H. Lee, V.H. Chu, Spreading of turbulent round jet in coflow, J. Hydraul. Eng. 125(2) (1999) 193-204.

[65] G. Balarac, O. Métais, The near field of coaxial jets: A numerical study, Phys. Fluids 17(6) (2005) 065102.

[66] M. Uddin, A. Pollard, Self-similarity of coflowing jets: The virtual origin, Phys. Fluids 19(6) (2007) 068103.

[67] M. Favre-Marinet, E.B. Camano, J. Sarboch, Near-field of coaxial jets with large density differences, Exp. Fluids 26(1) (1999) 97-106. 